Western University Scholarship@Western

1997

\title{
Flat Tax Reform: A Quantitative Exploration
}

Gustavo Ventura

Follow this and additional works at: https://ir.lib.uwo.ca/economicsresrpt

Part of the Economics Commons

Citation of this paper:

Ventura, Gustavo. "Flat Tax Reform: A Quantitative Exploration." Department of Economics Research Reports, 9706. London, ON: Department of Economics, University of Western Ontario (1997). 
ISSN:0318-725X

ISBN:0-7714-2022-6

\author{
RESEARCH REPORT 9706 \\ Flat Tax Reform: \\ A Quantitative Exploration \\ by \\ Gustavo Ventura \\ ECONGMACS REFERENCE CENTRE \\ NOV 101997 \\ UNIVERSTY OF WESTERN ONTARIO
}

November 1997

\author{
Department of Economics \\ Social Science Centre \\ University of Western Ontario \\ London, Ontario, Canada \\ N6A 5C2 \\ econref@sscl.uwo.ca
}




\title{
Flat Tax Reform: A Quantitative Exploration
}

\author{
Gustavo Ventura*
}

\begin{abstract}
This paper explores quantitatively the general equilibrium implications of a revenue neutral tax reform in which the current income and capital income tax structure in the U.S. is replaced by a flat tax, as proposed by Hall and Rabushka (1995). The central aspects of such reform, the impact of tax reform on capital accumulation, labor supply and welfare, as well as its distributional consequences, are analyzed in a dynamic general equilibrium model where key features of the actual tax code are modelled. The main results are that, i) the elimination of the actual taxation of capital income has an important and positive effect on capital accumulation; ii) mean labor hours typically decrease in the cases considered, but aggregate labor in efficiency units increases; iii) in all circumstances analyzed, the distributions of earnings, income and especially wealth become more concentrated; iv) in some cases, despite significant aggregate welfare gains, not all households benefit from tax reform.
\end{abstract}

JEL Classification Numbers: E62, H20.

KEYWORDS: Flat Tax, Dynamic General Equilibrium, Heterogeneous Agents.

\footnotetext{
*Department of Economics, University of Western Ontario, London, Ontario, CANADA N6A 5C2. E-mail: gustavo@scylla.sscl.uwo.ca. Phone: (519) 661 3500. Fax: (519) 661 3666. I would like to thank to Mark Huggett for continuous advice and comments. I would also like to thank Anne Villamil, Bart Taub, Kent Smetters, and seminar participants at Illinois, Western Ontario, Centro de Investigacion Economica (ITAM) and C.I.D.E. (Mexico) for comments, and the Econometrics Lab at the University of Illinois for computer facilities. All errors are mine.
} 


\section{Introduction}

Recently, various proposals to drastically reformulate the tax code have been advanced in the United States. One such proposal for fundamental tax reform, the so called flat tax, has received considerable attention. In a nutshell, the proposed reform consists of the replacement of existing federal income and capital income taxes by a single tax rate applied to labor income above a given threshold, and all (gross) capital income after full investment deductibility. What are, in quantitative terms, the consequences of such drastic reform? It is clear that a careful assessment of the changes generated by a flat tax is of particular importance given that the impact of such drastic reform is expected to be widespread. For instance, recent debates have emphasized issues such as the greater simplicity and fairness of the resulting tax code after the reform, decreased compliance costs of a flat tax as compared to the actual tax structure, the removal of deadweight losses implied by the current progressive income tax, growth effects, distributional considerations, etc ${ }^{1}$.

This paper focuses on two central and conflicting issues of the flat tax debate. Since a flat tax is a form of consumption taxation that removes distortions associated with the existence of a progressive income tax and the (double) taxation of capital income, flat tax proponents argue that its positive effects on aggregate capital accumulation, labor supply and welfare are expected to be of considerable magnitude. On these grounds, the shift towards a flat tax is viewed as highly desirable. However, as some critics point out, a flat tax reform may adversely affect the cross-sectional income and wealth distribution. Moreover, as a form of consumption taxation, a flat tax implies a shift of the overall tax burden towards the elderly, and away from young agents ${ }^{2}$. To sum up, these considerations actually suggest that the quantitative exploration of a flat tax reform is an important subject. Nevertheless, little is yet known at the quantitative level about the probable long run effects on the U.S. economy of a shift to a flat tax. This is presumably due to the relative complexity involved in modelling in a realistic form the actual progressive income taxes, as well as to the difficulties associated with the construction of general equilibrium models capable of

\footnotetext{
${ }^{1}$ See Hall and Rabushka (1995) for the seminal reference on the flat tax. Herman and Sease (1996) contains a nice and readable account of the different proposals, and the debate over the flat tax.

${ }^{2}$ This point is stressed by Kotlikoff (1995).
} 
matching distributional features of actual economies.

As discussed above, the replacement of the actual forms of income and capital income taxation by a flat tax is expected to impact on the levels of aggregate labor hours and capital accumulation, the corresponding factor prices, welfare, and the distribution of income and wealth among households. This observation provokes in turn a multitude of specific questions regarding the overall effects of such reform. For example,

- What is the impact of the flat tax reform on capital accumulation? How high must the flat tax rate be so that the reform is revenue neutral?

- Does the pre-tax income distribution change substantially with the reform? Does the after-tax income distribution become more unequal?

- How do the earnings, income and wealth Gini coefficients under a flat tax code compare to the Gini coefficients under the current structure?

- How do the percentages of income earned by agents at different percentiles of the income distribution compare between the two tax systems?

- How is aggregate labor supply affected? What is the impact of a flat tax reform on the distribution of labor hours?

- Are there welfare gains from moving to a flat tax? If so, is it the case that all households benefit from the tax reform?

The aim of this paper is thus to explore the general equilibrium consequences of a revenue neutral tax reform, in which an income and capital income tax structure designed to mimic the prevailing structure in the U.S. is replaced by a flat tax. In order to properly attack this problem, the model economies considered in this paper are populated by complex forms of heterogeneous agents. I study life cycle economies in which agents live for a realistic number of periods, face uncertain lifetimes, have preferences over consumption and leisure, and differ in terms of their position in the life cycle (age) as well as in their earnings histories. risk-free asset to provide for retirement income and insure themselves against lifetime uncertainty and fluctuations experienced in the market return to labor. Finally, there exists a pay-as-you-go Social Security scheme, with similar features to the one actually in place in the U.S. 
It is important to point out that model economies with the features outlined above are particularly useful in the study of flat tax reform. There are mainly two reasons for this. First, this modelling framework is capable of handling realistic representations of the actual tax structure and the proposed flat tax reform. Second, the model economies are capable of approximating reasonably well distributional features of actual economies ${ }^{3}$. This point is key, as one of the objectives of the present paper is to understand the effects of a flat tax on the distributions of earnings, income and wealth.

The main findings of the paper are that, first, the elimination of the current taxation of capital income has an important impact on capital accumulation. Second, the introduction of a flat tax determines that aggregate labor hours typically fall in most of the cases considered. However, mean labor hours of households at the top of the income distribution (who are highly productive) substantially increase. This latter effect implies an increase in the aggregate quantity of the labor input. Third, in all the circumstances analyzed, the distribution of earnings, income and especially wealth, become more concentrated. Finally, the aggregate welfare gains generated by the tax reform are quantitatively significant. In the benchmark calculations, welfare gains are in the range of a $2.7 \%$ to $1.2 \%$ increase in consumption at all ages and states for all agents. Nevertheless, an exploration of the distribution of welfare gains demonstrates that in some cases not all households benefit from the tax reform.

The paper proceeds as follows. Section 1 describes the basic flat tax reform proposal. Section 2 describes in detail the model economies. Section 3 discusses the details of the calibration process. Section 4 presents the main findings of the paper in terms of the aggregate impact of a flat tax and its distributional effects. Section 5 deals with the welfare gains of tax reform. Section 6 studies the role of accidental bequests in the results. Finally, section 7 concludes.

\footnotetext{
${ }^{3}$ See Quadrini and Rios-Rull (1996) for an overview of the distributional implications of economies with heterogeneous agents. See Huggett (1996) and Huggett and Ventura (1997) for the distributional implications of life cycle economies with heterogeneous agents.
} 


\section{$1 \quad$ Flat Tax Reform}

As originally conceived by Robert Hall and Alvin Rabushka in the early eighties, the main objective of the so called flat tax is to create a form of progressive consumption taxation to replace the actual personal income tax and the corporation income tax in the U.S. The tax system proposed by Hall and Rabushka (1995) comprises two different, but consistent forms of taxation. The first one is called "wage tax". This part of the flat tax plan taxes the sum of all wages, salaries and pensions above a given labor income threshold. The marginal tax rate is flat (constant) above the threshold, which implies, of course, that average taxes paid are increasing in the amount of labor income. It is here, in the wage tax, where the progressive part of the proposal lies. In this regard, the notion of progressivity embodied in the flat tax is different from the one in the actual income tax, in which both marginal and average tax rates are increasing.

The second part of the flat tax plan is the "business tax". Since the objective is an integrated consumption-based tax, this new instrument is designed to tax all income which is not labor income or investment. Consequently, the business tax imposes a flat rate (the same rate as the wage tax) on all corporate and non-corporate business income less wages and employer's pension contributions, purchases of inputs from other firms, and investment. In other words, in the aggregate, the business tax imposes a flat rate on all capital income after net capital accumulation.

Some remarks about the nature and possible implications of a flat tax are now in order. As just described in the above paragraphs, with a proposed flat tax rate set around $20 \%$, and an actual income tax with graduated rates at $15 \%, 28 \%, 31 \%, 36 \%$ and $39.6 \%$, this new form of taxation reduces quite substantially marginal tax rates on labor income for upper-middle and upper income households. However, depending upon the exemption levels chosen, the marginal tax rate for households previously in the $15 \%$ tax bracket may or may not increase. Even though the final impact on labor supply is unknown, there is room for potential increases in hours worked, in particular for households in the upper tax brackets. Furthermore, since it fully removes the income tax and the corporate income tax, the flat tax proposal eliminates the present double taxation of capital income, and it does it in a crucial way. Due to the fact that the flat tax is a form of consumption taxation, it does not affect on the margin the asset accumulation decision. That is, in the 
simplest case, the marginal rate of substitution between consumption today and consumption tomorrow is not affected by the tax rate ${ }^{4}$. This suggests that an important general equilibrium effect is possible on capital accumulation and factor prices. Finally, the combined effects of the change in the degree of progressivity and the removal of distortions hint that important distributional changes are likely to occur. Consider, for example, the intuitive case of the earnings distribution. Here, the flat tax proposal contains the ingredients to make this distribution more concentrated. If the exemption level on labor income is set not too high, the flat tax may reduce the labor supply of agents at the bottom of the earnings distribution. Simultaneously, if substitution effects prevail, the adoption of the flat tax will increase the labor hours supplied of households at the top percentiles of such distribution. These considerations together dictate that the distribution of labor earnings is likely to become more concentrated.

\section{The Economies Investigated}

I study a general equilibrium - life cycle economy populated by heterogeneous agents ${ }^{5}$. The novelty in the present formulation is the introduction

\footnotetext{
${ }^{4}$ To see this point, consider the simple case of a two-period model in which an agent chooses consumption in both periods $\left(c_{1}\right.$ and $\left.c_{2}\right)$, saves the amount $s$, and receives labor income $w_{1}$ and $w_{2}$. Under an income tax $t_{y}$ applied on income $w+r s$, and a capital income $\operatorname{tax} t_{s}$ applied on $r s$, the present value budget constraint for such an agent is

$$
c_{1}+c_{2} /\left(1+r\left(1-t_{y}-t_{s}\right)\right) \leq\left(1-t_{y}\right)\left(w_{1}+w_{2} /\left(1+r\left(1-t_{y}-t_{s}\right)\right)\right)
$$

First order conditions for optimal choice of consumption in both periods are $U^{\prime}\left(c_{1}\right)=$ $\beta\left(1+r\left(1-t_{y}-t_{s}\right)\right) U^{\prime}\left(c_{2}\right)$, where $\beta$ is the discount factor. Clearly, the marginal rate of substitution between $c_{1}$ and $c_{2}$ is affected by the tax rates. Under a consumption tax $t_{c}$, the present value budget constraint becomes

$$
\left(1+t_{c}\right)\left(c_{1}+c_{2} /(1+r)\right) \leq w_{1}+w_{2} /(1+r)
$$

First order conditions are now $U^{\prime}\left(c_{1}\right)=\beta(1+r) U^{\prime}\left(c_{2}\right)$. Consequently, the marginal rate of substitution between $c_{1}$ and $c_{2}$ is unaffected by the tax rate on consumption.

${ }^{5}$ The modelling framework used here is similar to that used by Imrohoroglu et al (1995), Huggett (1996), and Huggett and Ventura (1997). Also similar frameworks appear in Laitner (1992), Rios-Rull (1996) and Imrohoroglu (1992). For a general discussion of economies with heterogeneous agents, see Rios-Rull (1995).
} 
of endogeneous labor supply together with realistic (progressive) forms of taxation, capable of approximating the actual tax structure as well as the flat tax proposal advanced by Hall and Rabushka (1995) ${ }^{6}$.

Demographics: Each period a continuum of agents are born. Agents live a maximum of $N$ periods and face a probability $s_{j}$ of surviving up to age $\mathrm{j}$ conditional upon being alive at age $\mathrm{j}-1$. Population at time $t$ is denoted by $N_{t}$, and grows at a constant rate $n$. The demographic structure is stationary, such that age $\mathrm{j}$ agents always constitute a fraction $\mu_{j}$ of the population at any point in time. ${ }^{7}$

Preferences: All agents have preferences over streams of consumption and leisure, represented by the following utility function:

$$
E\left[\sum_{j=1}^{N} \beta^{j}\left(\prod_{i=1}^{j} s_{i}\right) u\left(c_{j, t}, 1-l_{j, t}\right)\right]
$$

where $c_{j, l}$ and $l_{j, t}$ denote consumption and labor supplied at age $j$ and period $t$ respectively. Agents are endowed with one unit of time at each age. The period utility function $u(c, 1-l)$ belongs to the constant relative risk aversion class. Furthermore, the period utility function displays intratemporal elasticity of substitution between consumption and leisure equal to $1, \nu$ being the coefficient of consumption vs. leisure. Hence, the utility function has the form

$$
u(c, l)=\frac{\left[c^{\nu}(1-l)^{1-\nu}\right]^{(1-\sigma)}-1}{(1-\sigma)}
$$

Technology: At any time period $t$ there is a constant returns to scale production technology that transforms capital $K$ and labor $L$ into output $Y$. This technology is represented by a Cobb-Douglas production function. The

\footnotetext{
${ }^{6}$ Auerbach and Kotlikoff $(1987$, ch. 8$)$ introduced progressive income taxes in their pathbreaking work. The framework studied here, however, is richer in the sense that progressive taxes in model economies are imposed over brackets of income or labor income, as it is actually the case in the U.S. and in the Hall-Rabushka proposal. This realistic modelling of progressive taxes has also been implemented recently by Engen and Gale (1996).

${ }^{7}$ The weights $\mu_{j}$ are normalized to sum to 1 , and are given by the recursion $\mu_{j+1}=$ $\left(s_{j+1} /(1+n)\right) \mu_{j}$.
} 
technology improves over time because of labor augmenting technological change. The technology level $X_{t}$ grows at a constant rate, $g$. Therefore,

$$
Y=F(K, L X)=A K^{\alpha}(L X)^{1-\alpha}
$$

The capital stock depreciates at the constant rate $\delta$.

Individual Constraints: The market return per hour of labor supplied of an age $j$ agent at time $t$ is given by $w_{t} e(z, j)$, where $w_{t}$ is a wage rate common to all agents, and $e(z, j)$ is a function that summarizes the combined productivity effects of age and of an idiosyncratic productivity shock $z$. The shock $z$ lies in the bounded set $\mathcal{Z} \subset \Re$ and follows a Markov process, with transition probabilities $p\left(z^{\prime}, z\right)$. Shocks received by age 1 agents are distributed according to the probability measure $q(z)$. Productivity shocks are assumed to be independently distributed across agents, and the law of large numbers is assumed to hold. This determines that no uncertainty will exist in the aggregate, even though uncertainty over the market return to labor supplied will prevail at the individual level.

All agents are born with no assets, and face mandatory retirement at age $j=R$. This determines that agents are allowed to work only up to age $R$ (inclusive). An age $j$ agent with idiosyncratic shock $z$ chooses consumption $c_{j, t}$, labor hours $l_{j, t}$ and risk-free asset holdings $a_{j+1, t+1}$. The budget constraint for such an agent is then

$$
\begin{aligned}
c_{j, t}+a_{j+1, t+1} & \leq a_{j, t}\left(1+r_{t}\right)+(1-\theta) w_{t} e(z, j) l_{j, t}+T R_{t}+b_{j, t}-T_{j, t} \\
c_{j, t} \geq 0, a_{j, t} & \geq \underline{a_{t}} \text { and } a_{j+1, t+1} \geq 0 \text { if } j=N
\end{aligned}
$$

where $a_{j, t}$ are asset holdings at age $j$ and time $t, T R_{t}$ is an (age independent) lump-sum transfer of accidental bequests, $T_{j, t}$ are taxes paid, $\theta$ is the (flat) payroll social security tax and $b_{j, t}$ is the social security transfer. Asset holdings pay a risk-free return $r_{t}$. The constraint $a_{j, t} \geq \underline{a}_{t}$ implies that agents face a borrowing constraint. In addition, if an agent survives up to the terminal period $(j=N)$, then next period asset holdings must be non-negative. In other words, agents are not allowed to borrow when the probability of surviving up to the next period equals zero. The social security benefit $b_{j, t}$ is 
zero before the retirement age $R$ and equals a fixed benefit level for an agent after retirement ${ }^{8}$.

Taxes and Government Consumption: In the model economies considered, the government consumes in every period the amount $G_{t}$, which is financed only through taxation. Since the purpose of the paper is to analyze the impact of a flat tax reform, I consider two generic tax regimes in the model economies. In the first one, designed to mimic the current tax structure in the U.S., there is a progressive income tax, as well as a flat capital income tax at rate $\tau_{k}$. The income tax is comprised of $M$ different brackets, defined by thresholds $I_{0}, I_{1}, I_{2}, \ldots I_{M}$, with corresponding marginal tax rates $\tau_{m}, m=1, \ldots M$. An agent's income subject to taxation is defined to be labor plus asset income. Consequently, an age $j$ agent with an income $I \equiv w_{t} e(z, j) l_{j, t}+r_{t} a_{j, t}$, with $I \in\left(I_{m-1}, I_{m}\right)$, pays the amount

$$
T_{j, t}=\tau_{1}\left(I_{1}-I_{0}\right)+\tau_{2}\left(I_{2}-I_{1}\right)+\ldots+\tau_{m}\left(I-I_{m-1}\right)+\tau_{k}\left[r_{t} a_{j, t}\right]
$$

In the second tax regime, that replicates the "business" and labor income taxes embodied in the flat tax proposals, agents pay rate $\tau_{b}$ on capital income after full deductibility of savings made ${ }^{9}$, and rate $\tau_{l}$ over all labor income above a threshold $I^{*}$. Therefore, total taxes paid by an age $\mathrm{j}$ agent receiving a shock $z$ amount to

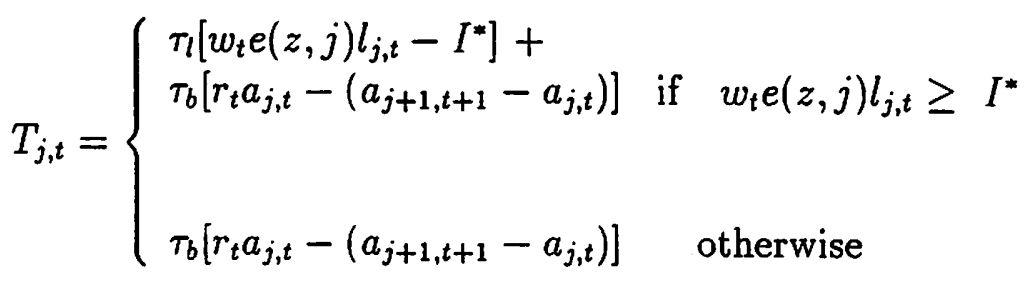

\footnotetext{
${ }^{8}$ Technical progress determines that in steady state the benefit level will grow over time at rate $g$. Thus, cohorts that retire later receive a higher benefit level. In the present formulation, social security transfers are completely independent of earnings histories, and thus equal the same amount for all cohort members after retirement. This is not the case under the U.S. system, in spite of the highly redistributive nature of the social security payments. This assumption is made because it greatly simplifies the numerical problem that must be solved. In particular, without this assumption the choice of labor hours becomes history dependent. The underlying reason is that a current choice of labor hours affects tomorrow's history of earnings, and thereby, the social security payments to be received after retirement. See Huggett and Ventura (1997) for an example on how to proceed with a more realistic formulation.

${ }^{9}$ Savings are defined as the change in asset holdings of households $\left(a_{j+1, t+1}-a_{j, t}\right)$.
} 
Notice that in this formulation, the "business" tax is paid by individual agents who are the economic units that accumulate capital (assets), and rent their asset holdings to firms at interest rate $r_{t}$ (the rental price of capital after subtracting depreciation). In a similar fashion, the capital income tax in the model economies, that mimics the current corporate income tax in the U.S., is paid by individual agents. For the questions at hand, this formulation is equivalent to one in which firms own capital, undertake investment decisions, and pay either the corporate income tax or the business tax.

\subsection{Recursive Formulation}

For computational purposes I transform variables in order to remove the consequences of growth. The transformations are standard: aggregate variables $G_{t}, K_{t}$ and $Y_{t}$ are divided by $N_{t} X_{t}$, aggregate labor is divided by $N_{t}$, and individual variables and factor prices that grow over time in steady state at the rate $g$, are divided by the technology level. The transformations proceed as follows:

$$
\begin{gathered}
\hat{a}_{t}=a_{t} / X_{t}, \hat{\hat{a}_{t}}=a_{t} / X_{t}, \hat{c}_{t}=c_{t} / X_{t}, T \hat{R}_{t}=T R_{t} / X_{t}, \hat{b}_{j, t}=b_{j, t} / X_{t}, \hat{l}_{j, t}=l_{j, t} \\
\hat{T}_{t}=T_{t} / X_{t}, \hat{G}_{t}=G_{t} /\left(N_{t} X_{t}\right), \hat{K}_{t}=K_{t} /\left(N_{t} X_{t}\right), \hat{L}_{t}=L_{t} / N_{t}, \hat{w}_{t}=w_{t} / X_{t}, \hat{r}_{t}=r_{t}
\end{gathered}
$$

With these transformations, an agent's decision problem can be described in standard recursive fashion. From now on, time subscripts are dropped, since I focus on stationary equilibria. An agent's state is denoted by the pair $x=(\hat{a}, z), x \in \mathcal{X}$, where $\hat{a}$ are current (transformed) asset holdings and $z$ is the idiosyncratic productivity shock. The set $\mathcal{X}$ is $\mathcal{X}=[\underline{\hat{a}}, \infty) \times \mathcal{Z}$. With some abuse of notation, I denote total taxes at state $(x, j)$ (income taxes plus capital income taxes in the first tax regime or wage plus business taxes in the second tax regime) by $T(x, j)$. Consequently, optimal decision rules are functions for consumption $c(x, j)$, labor $l(x, j)$, and next period asset holdings $a(x, j)$ that solve the following dynamic programming problem:

$$
V(x, j)=\max _{\left(\hat{\imath}, \hat{i}, \hat{a}^{\prime}\right)} u(\hat{c}, 1-\hat{l})+\beta(1+g)^{[\nu(1-\sigma)]} s_{j+1} E\left[V\left(\hat{a}^{\prime}, z^{\prime}, j+1\right) \mid x\right]
$$

subject to 
1. $\hat{c}+\hat{a}^{\prime}(1+g) \leq \hat{a}(1+\hat{r})+(1-\theta) \hat{w} e(z, j) l+\hat{T R}+\hat{b_{j}}-T(x, j)$

2. $\hat{c} \geq 0, \hat{a}^{\prime} \geq \underline{\hat{a}}$ and $\hat{a}^{\prime} \geq 0$ if $j=N$

3. $V(x, N+1) \equiv 0$

Some remarks about the above recursive problem are in order. First, given that the set $\mathcal{Z}$ is bounded, the fact that individuals have finite lifetimes implies that the age specific value functions are bounded. Second, notice that in the first tax regime, if the marginal income tax rates are increasing then the constraint set is convex. For the second tax regime, the constraint set is always convex. Therefore, when marginal tax rates are increasing, restriction (3) above and the fact that the period utility function is concave for all $j$ and $z \in \mathcal{Z}$, imply that the functions $V(., z, j)$ are concave. Consequently, optimal decision rules $a(x, j)$ and $l(x, j)$ are single valued. Finally, note that

the form of the first tax regime implies that both the utility function and the value functions are not differentiable everywhere. Therefore, standard first order conditions cannot generically be used to solve for decision rules. In the case of the second tax regime, once the budget constraint has been plugged into the period utility function, the period utility function is not differentiable everywhere with respect to labor hours. The reason is that the flat tax imposes a piecewise linear progressive tax scheme on labor income. These considerations determine that computationally fast methods that rely on first order conditions (Policy Function Iteration or a version of the Parametrizing Expectation Algorithm for instance) cannot in general be used to solve the agent's dynamic problem numerically.

\subsection{Equilibrium}

In the model economies, agents are heterogeneous with respect to the realization of their idiosyncratic labor productivity shock, their asset holdings, and their position in the life cycle (age). To specify the notion of equilibrium, a probability measure $\psi_{j}$ defined on subsets of the individual state space will describe the heterogeneity in assets and productivity shocks within a particular cohort. Let $\left(\mathcal{X}, B(\mathcal{X}), \psi_{j}\right)$ be a probability space where $B(\mathcal{X})$ is the Borel $\sigma$-algebra on $\mathcal{X}$. The probability measure $\psi_{j}$ must be consistent with individual decision rules that determine the asset position of individual agents 
at a given age, given the asset history and the history of labor productivity shocks. Therefore, it is generated by the law of motion of the productivity shock $z$ and the asset decision rule $a(x, j)$. The distribution of individual states across age 1 agents is determined by the exogenous initial distribution of labor productivity shocks $q(z)$, since agents are born with zero assets. For agents $j>1$ periods old, the probability measure is given by the recursion:

$$
\psi_{j+1}(B)=\int_{X} P(x, j, B) d \psi_{j}
$$

where

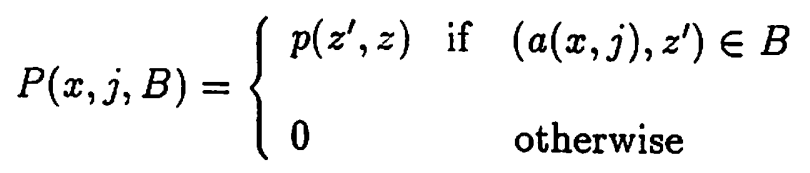

It is possible now to state the definition of steady state equilibrium:

Definition: A steady state equilibrium is a collection of decision rules $c(x, j), a(x, j), l(x, j)$, factor prices $\hat{w}$ and $\hat{r}$, taxes paid $T(x, j)$, a lump sum transfer of accidental bequests $\hat{T R}$, social security transfers $\hat{b}_{j}$, aggregate capital $\hat{K}$, aggregate labor $\hat{L}$, government consumption $\hat{G}$, a payroll tax $\theta, a$ tax regime $\in\{1,2\}$ and distributions $\left(\psi_{1}, \psi_{2}, \ldots, \psi_{N}\right)$ such that

1. $c(x, j), a(x, j)$ and $l(x, j)$ are optimal decision rules.

2. Factor Prices are determined competitively: $\hat{w}=F_{2}(\hat{K}, \hat{L})$ and $\hat{r}=$ $F_{1}(\hat{K}, \hat{L})-\delta$

3. Markets Clear:

(a) $\sum_{j} \mu_{j} \int_{X}(c(x, j)+a(x, j)(1+g)) d \psi_{j}+\hat{G}=F(\hat{K}, \hat{L})+(1-\delta) \hat{K}$

(b) $\sum_{j} \mu_{j} \int_{X} a(x, j) d \psi_{j}=(1+n) \hat{K}$

(c) $\sum_{j} \mu_{j} \int_{X} l(x, j) e(z, j) d \psi_{j}=\hat{L}$

4. Distributions are Consistent with Individual Behavior:

$$
\psi_{j+1}(B)=\int_{X} P(x, j, B) d \psi_{j}
$$

for $j=1, \ldots, N-1$ and for all $B \in B(X)$. 
5. Government Budget Constraint is satisfied:

$$
\hat{G}=\sum_{j} \mu_{j} \int_{X} T(x, j) d \psi_{j}
$$

\section{Social Security Benefits Equal Taxes: $\theta \hat{w} \hat{L}=\sum_{j=R}^{N} \mu_{j} \hat{b}_{j}$}

7. Transfers Equal Accidental Bequests:

$$
\hat{T R}=\left[\sum_{j} \mu_{j}\left(1-s_{j+1}\right) \int_{X}(a(x, j)(1+\hat{r})) d \psi_{j}\right] /(1+n)
$$

Conditions 1 thru 5 above are standard. Condition 6 and 7, however, require some explanation. Condition 6 implies budget balance for the social security system, and that such a system is funded on a pay-as-you-go basis. Condition 7 states that lump sum transfers $\hat{T R}$ equal per-capita accidental bequests. This formulation is obviously not a realistic feature of the U.S. economy. However, it is made in order to introduce lifetime uncertainty, and therefore realistic demographic patterns, in the simplest possible way.

\section{Calibration}

\subsection{Model Parameters}

The model period is considered to be one year. Based upon this choice of model period, parameters are selected as follows:

- Preferences: The coefficient of leisure vs. consumption $\nu$ is set equal to $0.33^{10}$. Two common values in the literature are adopted for the parameter $\sigma$. Results are reported for $\sigma=1.5$ and $\sigma=2.0{ }^{11}$. The remaining preference parameter, the discount factor $\beta$, is set equal to 1.011, following the estimation of Hurd (1989) of a discount factor in a life cycle setting that explicitly incorporates uncertain lifetimes.

\footnotetext{
${ }^{10}$ This is the value typically used in infinitely-lived models to match the fraction of time devoted to market work in steady state. It should be noted, as Rios-Rull (1996) does, that in life cycle models there is no straightforward relation between the fraction of time devoted to market work and $\nu$. Nevertheless, in the absence of a precise value for this parameter in a life cycle context, I use the estimate reported above $(\nu=.33)$.

${ }^{11}$ See Rios-Rull (1996) for a careful discussion on the importance of this parameter for generating reasonable values for the capital to output ratio in life cycle economies.
} 
- Technology: The capital share in output $\alpha$ is set equal to 0.36 , from Prescott (1986). Following Stokey and Rebelo (1995), the depreciation rate $\delta$ is set equal to 0.06 , in order to match the depreciation to output ratio in the U.S. The constant $A$ is a free parameter, so a value of 0.89594 is selected. Using $\alpha=0.36$, this choice implies that the wage rate is equal to 1.0 whenever the capital to output ratio equals 3.0 . Finally, the growth rate of the technology, $g$, takes the value 0.018 . This is the value for the growth in per-capita GDP for the period 19501992 in the U.S., as reported in the Economic Report of the President (1994).

- Demographics: Agents are born at a real life age of 20 , and the maximum possible lifetime is set equal to 100 years. This determines a value for $N$ equal to 81 . Agents retire at a real life age of 65 (model period 46). This implies $R=46$. The survival probabilities $s_{j}$ are those for U.S. men in 1992, as estimated in Social Security Administration (1992). The value for the rate of population growth $n$ is 0.012 , which is the average rate of population growth in the U.S. for the period 1950-1994 (Economic Report of the President (1996), table B32).

- Borrowing constraints: The lowest bound on asset holdings is set at zero $(\underline{\hat{a}}=0.0)$.

\subsection{Taxes and Government Consumption:}

The social security tax rate, $\theta$, common to both tax regimes, equals the average for the 1980s of the contribution to social security programs as a fraction of labor income. The data on contributions come from Table M3 of the Social Security Bulletin and exclude unemployment and disability insurance contributions. Thus, $\theta$ takes the value 0.094 . The calibration of the first tax regime proceeds as follows. The capital income tax adopts a value that matches the average tax collections from the corporate income tax in the U.S., as a fraction of GDP. For the period 1987-1994, these tax collections as a fraction of GDP averaged $1.87 \%$ (Economic Report of the President (1996), table B76). Hence, $t_{k}$ is obtained as follows. Let $C$ denote the gross value of the Corporate Income tax collections. Then, $\hat{C}=\tau_{k}(\hat{r} \hat{K})$, since $\hat{r} \hat{K}$ is the aggregate size of capital income. and $\hat{C} / \hat{Y}=0.0187$. Consequently, the 
capital income tax is determined endogenously in the model economies, and takes the value $t_{k}=\frac{0.0187}{\tilde{r} \bar{K} / \bar{Y}}$. The case of the income tax is substantially more complex. I calibrate the benchmark case to approximate the rough features of the income tax code in the U.S., prevailing after the 1994 reforms. The following table, based upon data in the Economic Report of the President (1994, pp. 34), describes the actual income tax in the U.S. for married couples filing jointly ${ }^{12}$ :

\section{Table 1}

\begin{tabular}{|l|l|}
\hline $\begin{array}{l}\text { Taxable } \\
\text { Income }\end{array}$ & $\begin{array}{l}\text { Marginal } \\
\text { Tax Rate }\end{array}$ \\
\hline $0,0.85$ & 0.15 \\
$0.85,2.06$ & 0.28 \\
$2.06,3.24$ & 0.31 \\
$3.24,5.79$ & 0.36 \\
5.79 and over & 0.396 \\
\hline
\end{tabular}

In order to calibrate the bendpoints $\hat{I}_{0}, \hat{I}_{1}, \ldots . \hat{I}_{M}$ and the corresponding marginal tax rates, it is important to approximate the complex exemptions and deductions present in the actual tax code. I take as a departing point the case of a household comprised of a couple filing jointly with two children, that take the standard deduction. In this context, the sum of the corresponding standard deduction plus four personal exemptions equaled $37.5 \%$ of the average household income in 1994. This implicitly defines a level of income such that all income below such level escapes income taxation. However, when approximately $71 \%-72 \%$ of tax returns took the standard deduction and $29 \%-28 \%$ itemized in 1994, itemized deductions accounted for $54.7 \%$ of all claimed deductions. Since the model economies considered in this paper do not allow agents to choose between the standard deduction and itemized deductions, I concentrate on the case in which the lowest level of income subject to taxation is equal to $50 \%$ of the mean household income of the model economy considered.

Once the lowest income level subject to income taxation is set, I use the previous table as a benchmark for the calibration of the bendpoints and the

\footnotetext{
${ }^{12}$ Taxable income is expressed in multiples of average household income, as reported by the Bureau of Census for 1994.
} 
marginal tax rates, expressed in terms of the multiples of mean household income $(\hat{\mathcal{I}})^{13}$ :

Table 2

\begin{tabular}{|l|l|}
\hline $\begin{array}{l}\hat{w} e(z, j) l(x, j) \\
+\hat{r} \hat{a}_{j}\end{array}$ & Marginal \\
\hline $0,0.5 \hat{\mathcal{I}}$ & 0.0 \\
$0.5 \hat{\mathcal{I}}, 1.35 \hat{\mathcal{I}}$ & 0.15 \\
$1.35 \hat{\mathcal{I}}, 2.56 \hat{\mathcal{I}}$ & 0.28 \\
$2.56 \hat{\mathcal{I}}, 3.74 \hat{\mathcal{I}}$ & 0.31 \\
$3.74 \hat{\mathcal{I}}, 6.29 \hat{\mathcal{I}}$ & 0.36 \\
$6.29 \hat{\mathcal{I}}$ and over & 0.396 \\
\hline
\end{tabular}

Hence, $\hat{I}_{0}=0, \hat{I}_{1}=0.5 \hat{\mathcal{I}}, \hat{I}_{2}=1.35 \hat{\mathcal{I}}, \hat{I}_{3}=2.56 \hat{\mathcal{I}}, \hat{I}_{4}=3.74 \hat{\mathcal{I}}$, and $\hat{I}_{5}=6.29 \hat{\mathcal{I}}$. Once the two sources of tax collections have been parametrized, the value of government consumption is determined endogenously by the equilibrium condition 5 . As a consequence, the interpretation of $\hat{G}$ in the model economies under tax regime 1 is the size of tax collections out of capital income and income taxes. Since the purpose of the paper is to consider a revenue neutral tax reform, tax regime 2 (the flat tax case) is parametrized using the value of $\hat{G}$ from the corresponding calculations for the first regime. Notice that tax collections in the case of a flat tax equal

$$
\sum_{j} \mu_{j}\left[\tau_{l} \int_{\mathcal{A}} \hat{w} e(z, j) l(x, j) d \psi_{j}(x)+\tau_{b} \int_{X}(\hat{r} \hat{a}-(a(x, j)(1+g)-\hat{a})) d \psi_{j}(x)\right]
$$

with $\mathcal{A}=\left\{x \in X: \hat{w} e(z, j) l(x, j) \geq \hat{I}^{*}\right\}$.

In order to satisfy the above government budget constraint, values for $\hat{I}^{*}$ must be specified. To preserve comparability across model economies and tax regimes, results are reported for different exemption values as multiples of the mean income $(\hat{\mathcal{I}})$ of the corresponding model economy under the first tax regime. With $\hat{I}^{*}$ and $\hat{G}$ at hand, provided that in the baseline Hall-Rabushka (1995) proposal the flat tax rate is $\tau_{b}=\tau_{l} \equiv \tau$, the flat tax rate is obtained by updating its value after an initial guess at every iteration in the computation of equilibria, until the government budget constraint is satisfied.

\footnotetext{
${ }^{13}$ The concept of income utilized in the computation of $(\hat{\mathcal{I}})$ is labor plus asset income before taxes plus all transfers.
} 


\subsection{The stochastic structure of wages}

Recently, some models with heterogeneous agents and no labor supply decision have been calibrated using a regression to the mean process for labor earnings (see Huggett (1996) for example). The calibration adopted by these papers cannot immediately be extended to the model economies analyzed here, because labor supply is endogenous in the current setup. I proceed to calibrate the market return per unit of labor time supplied, described by the function $e(z, j)$, under the assumption that the underlying stochastic structure also follows a regression to the mean process. Notice that since $\hat{w}$ is a constant at all ages and states. the calibration of the function $e(z, j)$ is equivalent to the calibration of a wage process over an agent's working life. Let $y_{j}$ and $\overline{y_{j}}$ denote the log market return and the mean log market return of an agent $\mathrm{j}$ periods old. Thus, the labor productivity shock is defined as $z \equiv y_{j}-\bar{y}_{j}$, which implies that the function $e(z, j)$ takes the form $e(z, j)=e^{\left(z+y_{j}\right)}$. Then, the market return to labor follows the regression to the mean process for all $1<j \leq R$ :

$$
y_{j}-\overline{y_{j}}=\gamma\left(y_{j-1}-y_{j-1}\right)+\epsilon_{j}
$$

with $\epsilon \sim N\left(0, \sigma_{\epsilon}^{2}\right)$. For $j=1, y_{1} \sim N\left(\overline{y_{1}}, \sigma_{y_{1}}^{2}\right)$.

The calibration of the wage process proceeds as follows. First, the age specific pattern of mean log wages $\overline{y_{1}}, \ldots, \overline{y_{R}}$ is chosen. I approximate this by using the wage profile computed by Hansen (1993) ${ }^{14}$. The profile is displayed in figure 1.

Insert figure 1 here

Second, I need to set values for the remaining parameters of the wage process $\left(\gamma, \sigma_{\epsilon}^{2}, \sigma_{y_{1}}^{2}\right)$. The natural avenue to select values for these parameters would be using i) data on the magnitude and persistence of idiosyncratic wage shocks and ii) data on the concentration of wages. Unfortunately, no data is available on the magnitude and persistence of shocks to log wages even though there is data measuring the concentration of wages. Thus, I proceed to select parameter values so that the implied wage distribution

\footnotetext{
${ }^{14}$ Linear interpolations are used to obtain the profile for all possible ages.
} 
matches some recent estimates of the concentration of wages. In this regard, Ryscavage (1994) finds that the wage Gini coefficient for all earners was 0.345 in 1989. This previous estimate can be taken as a lower bound since it understates the true degree of wage inequality (see Ryscavage (1994) for details). Based upon these considerations, I set $\gamma=0.985, \sigma_{y_{1}}^{2}=0.29$, and $\sigma_{\epsilon}^{2}=0.02$ as the baseline parameter values ${ }^{15}$. This choice determines that the Gini coefficient for wages equals 0.38 . As will be seen in the next section, this calibrated process for wages generates an earnings distribution in stationary equilibrium whose concentration statistics approximate recent estimates for the actual distribution in the U.S. Furthermore, the stationary income distribution implied by the heterogeneity generated by this wage process, closely tracks the actual income distribution in the U.S.

The wage process described above is discretized for computational purposes. The shock $z$ takes 21 possible values, evenly spaced in the log scale, ranging from $-5 \sigma_{y_{1}}$ to $5 \sigma_{y_{1}}$. Probabilities $q(z)$ of receiving a particular shock for age 1 agents are computed by simple numerical integration of the normal distribution $N\left(0, \sigma_{y_{1}}^{2}\right)$. Transition probabilities $p\left(z^{\prime}, z\right)$ are obtained in a similar fashion.

\section{$4 \quad$ Results}

This section reports the basic quantitative findings for both tax regimes. Details on how equilibria are computed are described in Appendix 1.

\subsection{Tax Regime 1 .}

Table 3 below shows basic statistics for the model economies. These results are important, in the sense that they will be compared afterwards with the equivalent statistics for tax regime 2. Notice that the economy with $\sigma=1.5$ displays a higher degree of capital accumulation than the economy with $\sigma=$ 2.0 , as households in the latter case prefer a relatively smoother consumption profile, and thereby, lower rates of consumption growth.

\footnotetext{
${ }^{15}$ Other values for these parameters are explored in Appendix 2.
} 
Table 3: Descriptive Statistics for Tax Regime 1. ${ }^{16}$

\begin{tabular}{|l|ccccccc|}
\hline $\begin{array}{l}\text { Model } \\
\text { Economy }\end{array}$ & $\hat{K} / \hat{Y}$ & $\hat{L}$ & $\begin{array}{c}\text { Mean } \\
\text { Hours }\end{array}$ & $\hat{Y}$ & $\hat{w}$ & $\begin{array}{c}\hat{r} \\
(\%)\end{array}$ & $\begin{array}{c}\tau_{k} \\
(\%)\end{array}$ \\
\hline $\begin{array}{l}\sigma=2.0 \\
\sigma=1.5\end{array}$ & 3.25 & 0.343 & 0.289 & 0.563 & 1.05 & 5.1 & 11.3 \\
& 3.46 & 0.352 & 0.296 & 0.595 & 1.08 & 4.4 & 12.2 \\
\hline
\end{tabular}

In order to take seriously the distributional impact of flat tax reform to be computed later, it is key to check against actual data some statistics on the stationary distributions of income, earnings and wealth in tax regime 1. These statistics are displayed in the following tables 4 and 5 . In terms of a measure such as the Gini coefficient, the model economies generate a concentration of earnings and income that closely matches recent estimates for the U.S. In this regard, Henle and Ryscavage (1990) report that the earnings Gini coefficient for all earners in the period 1985 to 1988 averaged 0.47 , and that in 1988 the percent share in aggregate earnings of the lowest, second, third, fourth and upper quintiles was $2.1,8.3,15.8,25.2$, and 48.6 respectively ${ }^{17}$. Notice that both model economies approximate the earnings Gini. Moreover, the model economies also generate similar values for the share of aggregate earnings earned by different quantiles. For example, in the case of $\sigma=1.5$, the percent share in aggregate earnings of the lowest to the highest quintiles is $3.0,8.6,13.5,23.0$, and 51.8 respectively.

\footnotetext{
${ }^{16}$ The value for mean hours represents the mean fraction of discretionary time spent working by agents who are 65 years old or younger. Therefore, it equals

$$
\left[\sum_{j=1}^{R} \mu_{j} \int_{X} l(x, j) d \psi_{j}\right] / \sum_{j=1}^{R} \mu_{j}
$$

${ }^{17}$ These measures tend to understate the true degree of earnings concentration, due to several data problems. See Henle and Ryscavage (1990) for details.
} 
Table 4: Distributional Features for Tax Regime 1.

\begin{tabular}{|l|ccccccc|}
\hline $\begin{array}{l}\text { Model } \\
\text { Economy }\end{array}$ & $\begin{array}{c}\text { Earnings } \\
\text { Gini }\end{array}$ & $\begin{array}{c}\text { Wealth } \\
\text { Gini }\end{array}$ & $\begin{array}{c}\text { Income } \\
\text { Gini }\end{array}$ & $\begin{array}{c}\text { Mean } \\
\text { Income }\end{array}$ & $\begin{array}{c}\text { Median } \\
\text { Income }\end{array}$ & $\begin{array}{c}\text { Mean } \\
\text { Wealth }\end{array}$ & $\begin{array}{c}\text { Median } \\
\text { Wealth }\end{array}$ \\
\hline & & & & & & & \\
$\sigma=2.0$ & 0.48 & 0.60 & 0.43 & 0.503 & 0.336 & 1.82 & 1.03 \\
$\sigma=1.5$ & 0.48 & 0.60 & 0.43 & 0.528 & 0.346 & 2.06 & 1.18 \\
\hline
\end{tabular}

Table 5: Percent Share of Income Earned by Quantiles.

\begin{tabular}{|l|ccc|ccccc|}
\hline Model & Top & Top & Top & \multicolumn{5}{|c|}{ Quintile } \\
Economy & $1 \%$ & $5 \%$ & $10 \%$ & 1st & 2nd & 3rd & 4th & 5th \\
\hline$\sigma=2.0$ & 6.8 & 21.1 & 33.0 & 5.6 & 10.0 & 13.4 & 22.3 & 48.7 \\
$\sigma=1.5$ & 6.7 & 21.3 & 33.2 & 5.5 & 10.0 & 13.2 & 22.4 & 49.0 \\
& & & & & & & & \\
\hline
\end{tabular}

The model economies also perform reasonably in terms of the implied income distribution along different dimensions ${ }^{18}$. In this regard, recent studies have documented extensively several features of the income distribution in the U.S., and its time path. Using data from the Consumer Population Survey for the case of income after transfers and before taxes, Ryscavage (1995) reports that the income Gini was $0.428,0.428,0.433,0.434$ and 0.447 for $1990,1991,1992$ and 1993 respectively. He also reports that in 1993, the share received by each quintile was $3.6,9.0,15.1,23.5$, and 48.9 , and that the top $5 \%$ of households earned approximately $20 \%$ of aggregate income. Table 5 shows that results obtained for the share of income of the different quantiles resemble the actual ones mentioned above. The match is particularly good for the share of income earned by the upper $20 \%$ of the distribution. Likewise, as Table 4 demonstrates, the model economies generate reasonable

\footnotetext{
${ }^{18}$ The concept of income used for the reported distributional calculations is labor plus asset income before taxes, plus all transfers.
} 
values for the income Gini. The model economies, nonetheless, do not concentrate enough income in the extreme upper tail (top 1\%) of the income distribution, as other studied have documented ${ }^{19}$.

The results obtained for the case of the wealth distribution, however, are not as satisfactory as for the case of income and earnings. The model economies generate substantially more concentration of wealth than income, as is the case in the actual data. Nevertheless, the implied wealth distribution is not as concentrated as the actual one. As a consequence, the model economies generate Gini coefficients ranging from 0.60 to 0.61 , that fall short of estimates for the U.S. ${ }^{20}{ }^{21}$.

How are labor hours supplied distributed across households in tax regime 1? This question is interesting from a quantitative viewpoint, since a flat tax is likely to have a significant impact on labor hours for households with different earnings abilities. Table 6 shows the results for mean labor hours at different percentiles of the income distribution.

Table 6: Mean Labor Hours at Different Income Quintiles.

\begin{tabular}{|l|cccc|ccccc|}
\hline Model & Top & Top & Top & $80-$ & \multicolumn{5}{|c|}{ Quintile } \\
Economy & $1 \%$ & $5 \%$ & $10 \%$ & $90 \%$ & 1st & 2nd & 3rd & 4th & 5th \\
\hline$\sigma=2.0$ & 0.377 & 0.360 & 0.350 & 0.307 & 0.239 & 0.280 & 0.271 & 0.319 & 0.327 \\
$\sigma=1.5$ & 0.398 & 0.382 & 0.367 & 0.319 & 0.239 & 0.295 & 0.276 & 0.327 & 0.340 \\
\hline
\end{tabular}

Notice that mean labor hours increase as the quintiles of income increase, with the exception of the third quintile. Also notice the important degree of heterogeneity in labor hours supplied. Households in the 5 th income quintile work $42-43 \%$ and $36-37 \%$ more than households in the lowest quintile, for $\sigma=1.5$ and $\sigma=2.0$ respectively.

\footnotetext{
${ }^{19}$ For instance, Avery and Kennickell (1993) using data from the Survey of Consumer Finances report that the top $1 \%$ of U.S. households earned $12.9 \%$ in 1986.

${ }^{20}$ Wolff (1987) reports that the U.S. wealth Gini is 0.72 . More recently, Quadrini and Rios-Rull (1996) find a similar value of 0.715 .

${ }^{21}$ See Huggett (1996) for a discussion of the implications of heterogenous agents-life cycle models without labor supply in terms of the wealth distribution. See also Quadrini (1996) for a recent contribution on this topic that emphasizes the role of entepreneurship.
} 
One of the functions frequently attributed to a tax code is its capacity to reduce inequality among households. Thus, it is important to know how effective tax regime 1 is in reducing the degree of income inequality, in order to compare these results later with those for tax regime 2. Table 7 shows the distribution of income after income and capital income taxes.

Table 7: After Tax Income Distribution in Tax Regime 1.

\begin{tabular}{|l|c|ccc|ccccc|}
\hline $\begin{array}{l}\text { Model } \\
\text { Economy }\end{array}$ & $\begin{array}{c}\text { Income } \\
\text { Gini }\end{array}$ & $\begin{array}{c}\text { Top } \\
\text { 1\% }\end{array}$ & $\begin{array}{c}\text { Top } \\
5 \%\end{array}$ & $\begin{array}{c}\text { Top } \\
\text { 10\% }\end{array}$ & 1st & 2nd & 3rd & 4th & 5th \\
\hline & & & & & & & & & \\
$\sigma=2.0$ & 0.39 & 5.7 & 18.4 & 29.4 & 6.1 & 11.2 & 14.4 & 23.1 & 45.2 \\
$\sigma=1.5$ & 0.39 & 5.7 & 18.4 & 29.6 & 6.1 & 11.2 & 14.4 & 23.0 & 45.3 \\
& & & & & & & & & \\
\hline
\end{tabular}

The findings displayed in table 7 show that the progressive structure of the income tax in tax regime 1 is indeed capable of reducing income inequality in an important way. Notice that the after tax income Gini coefficients are reduced from 0.43 to 0.39 . Notice also that the percentage shares of income are all adjusted, so that the after tax income distribution becomes less concentrated. For instance, observe that the share of the 5th quintile is reduced by 3.5 and 3.7 percentage points for the cases of $\sigma=2.0$ and $\sigma=1.5$ respectively.

\subsection{Tax Reform}

Results for the revenue neutral tax reform are displayed for three different exemption levels, $20 \%, 30 \%$ and $40 \%$ of the mean income $(\hat{\mathcal{I}})$ of the corresponding model economy under tax regime 1 . Table 8 shows descriptive statistics for the model economies under a flat tax. 


\section{Table 8: Descriptive Statistics for Tax Regime 2.}

\begin{tabular}{|l|ccccccc|}
\hline Model & $\hat{K} / \hat{Y}$ & $\hat{L}$ & $\begin{array}{c}\text { Mean } \\
\text { Hours }\end{array}$ & $\hat{Y}$ & $\hat{w}$ & $\begin{array}{c}\hat{r} \\
(\%)\end{array}$ & $\begin{array}{c}\tau \\
(\%)\end{array}$ \\
\hline$\sigma=2.0$ & & & & & & & \\
$\hat{I}^{*}=0.2 \hat{\mathcal{I}}$ & 3.74 & 0.357 & 0.288 & 0.630 & 1.13 & 3.6 & 20.5 \\
$\hat{I}^{*}=0.3 \hat{I}$ & 3.74 & 0.350 & 0.283 & 0.618 & 1.13 & 3.6 & 24.5 \\
$\hat{I}^{*}=0.4 \hat{\mathcal{I}}$ & 3.75 & 0.341 & 0.280 & 0.605 & 1.13 & 3.6 & 29.0 \\
\hline$\sigma=1.5$ & & & & & & & \\
$\hat{I}^{*}=0.2 \hat{I}$ & 3.95 & 0.366 & 0.292 & 0.668 & 1.17 & 3.1 & 21.5 \\
$\hat{I}^{*}=0.3 \hat{\mathcal{I}}$ & 3.95 & 0.359 & 0.287 & 0.658 & 1.17 & 3.1 & 25.5 \\
$\hat{I}^{*}=0.4 \hat{\mathcal{I}}$ & 3.96 & 0.350 & 0.280 & 0.642 & 1.17 & 3.1 & 31.0 \\
& & & & & & & \\
\hline
\end{tabular}

A key quantitative finding here is that the flat tax has a significant impact on capital accumulation. As shown in table 8, capital income ratios, output and wages increase substantially with respect to tax regime 1 , and interest rates decrease for all exemption levels considered. For instance, in the case of $\sigma=2.0$ and $\hat{I}^{*}=0.2 \hat{\mathcal{I}}$, the wage rate increases by about $7-8 \%$, output increases by $11-12 \%$, and the interest rate drops by 1.5 percentage points. The main reason behind this crucial finding is the removal of the double taxation of capital income, and its replacement by a consumption-based form of taxation. This is the case, provided that the flat tax eliminates the distortion associated with capital income taxation, by now making the after tax rate of return on an aditional unit of capital equal to its market return. The impact of this in general equilibrium is quite important, as table 8 demonstrates ${ }^{22}$.

Table 8 also shows that, with the exception of the economies with $\hat{I}=0.4$, aggregate labor input increases with respect to tax regime 1 , and in apparent contradiction, aggregate labor hours decrease in all cases. In the worst case scenario for aggregate labor hours, the case of an exemption level of $40 \%$,

\footnotetext{
${ }^{22}$ This finding parallels results provided by several authors. See Auerbach and Kotlikoff (1987) for example, for an assesment of the quantitative impact on capital accumulation of consumption taxes versus other forms of taxation.
} 
aggregate hours drop by $3.2-3.3 \%$ for $\sigma=2.0$, and $5.7-5.8 \%$ for $\sigma=1.5$. The underlying reason for the increase in labor input and the simultaneous decrease in average hours, lies in the combined impact on the distribution of labor hours of income and substitution effects implied by changes in factor prices, changes in the lump sum transfer of accidental bequests, as well as in the new marginal tax rates and exemption levels faced by households under the flat tax. Table 9 shows the new structure of labor hours at different income percentiles.

Table 9: Mean Labor Hours at Different Income Quintiles.

\begin{tabular}{|l|cccc|ccccc|}
\hline Model & Top & Top & Top & $80-$ & \multicolumn{5}{c|}{ Quintile } \\
Economy & $1 \%$ & $5 \%$ & $10 \%$ & $90 \%$ & 1st & 2nd & 3rd & 4th & 5th \\
\hline$\sigma=2.0$ & & & & & & & & & \\
$\hat{I}^{*}=0.2 \hat{\mathcal{I}}$ & 0.395 & 0.416 & 0.399 & 0.350 & 0.220 & 0.243 & 0.273 & 0.310 & 0.373 \\
$\hat{I}^{*}=0.3 \hat{\mathcal{I}}$ & 0.393 & 0.412 & 0.393 & 0.340 & 0.240 & 0.227 & 0.254 & 0.296 & 0.365 \\
$\hat{I}^{*}=0.4 \hat{\mathcal{I}}$ & 0.391 & 0.401 & 0.384 & 0.327 & 0.249 & 0.269 & 0.232 & 0.278 & 0.354 \\
$\sigma=1.5$ & & & & & & & & & \\
$\hat{I}^{*}=0.2 \hat{\mathcal{I}}$ & 0.408 & 0.435 & 0.417 & 0.363 & 0.219 & 0.240 & 0.273 & 0.316 & 0.388 \\
$\hat{I}^{*}=0.3 \hat{\mathcal{I}}$ & 0.406 & 0.430 & 0.410 & 0.352 & 0.243 & 0.226 & 0.253 & 0.300 & 0.379 \\
$\hat{I}^{*}=0.4 \hat{\mathcal{I}}$ & 0.403 & 0.422 & 0.400 & 0.333 & 0.248 & 0.270 & 0.226 & 0.274 & 0.364 \\
\hline
\end{tabular}

Interestingly, the change in labor hours with respect to tax regime 1 varies across quintiles 1 to 4 , showing increases and decreases in labor hours supplied according to the cases considered. Nevertheless, the impact of the flat tax on labor hours of households in the highest quintile is always positive, reflecting both i) the effects of reductions in marginal tax rates on labor income, and ii) the effects of the change in the intertemporal incentives to accumulate assets. This increase is quite important, ranging from $14.1-14.0 \%$ to $8.2-8.3 \%$ for $\sigma=2.0$. and from $14.1-14.2 \%$ to $7.0-7.1 \%$ for $\sigma=1.5$. These positive changes in the labor supply of richer households, groups that contain an important fraction of households at the peak of their age-productivity cycle and a high fraction of households receiving high shocks, are the key factors behind the increase in total labor input in model economies other than those 
with $\hat{I}^{*}=0.4 \hat{\mathcal{I}}$. Therefore, the reason for the increase in labor input and the simultaneous decrease in average labor hours, is simply that additional hours of highly productive agents, are in all cases more than sufficient to compensate for the negative effects on aggregate labor input of relatively low productivity households.

Table 10 shows distributional aspects of the model economies under the flat tax. The results clearly show that the distributions of earnings, wealth and income are adversedly affected in all circumstances.

Table 10: Distributional Features of Tax Regime 2.

\begin{tabular}{|l|ccccccc|}
\hline Model & $\begin{array}{c}\text { Earnings } \\
\text { Economy }\end{array}$ & $\begin{array}{c}\text { Wealth } \\
\text { Gini }\end{array}$ & $\begin{array}{c}\text { Income } \\
\text { Gini }\end{array}$ & $\begin{array}{c}\text { Mean } \\
\text { Income }\end{array}$ & $\begin{array}{c}\text { Median } \\
\text { Income }\end{array}$ & $\begin{array}{c}\text { Mean } \\
\text { Wealth }\end{array}$ & $\begin{array}{c}\text { Median } \\
\text { Wealth }\end{array}$ \\
\hline$\sigma=2.0$ & & & & & & & \\
$\hat{I}^{*}=0.2 \hat{\mathcal{I}}$ & 0.52 & 0.70 & 0.47 & 0.554 & 0.346 & 2.36 & 0.842 \\
$\hat{I}^{*}=0.3 \hat{\mathcal{I}}$ & 0.51 & 0.69 & 0.47 & 0.541 & 0.329 & 2.32 & 0.831 \\
$\hat{I}^{*}=0.4 \hat{\mathcal{I}}$ & 0.50 & 0.68 & 0.46 & 0.528 & 0.307 & 2.28 & 0.915 \\
\hline$\sigma=1.5$ & & & & & & & \\
$\hat{I}^{*}=0.2 \hat{\mathcal{I}}$ & 0.53 & 0.70 & 0.47 & 0.576 & 0.355 & 2.65 & 0.924 \\
$\hat{I}^{*}=0.3 \hat{\mathcal{I}}$ & 0.52 & 0.70 & 0.47 & 0.562 & 0.333 & 2.59 & 0.895 \\
$\hat{I}^{*}=0.4 \hat{\mathcal{I}}$ & 0.51 & 0.68 & 0.46 & 0.545 & 0.309 & 2.54 & 1.040 \\
& & & & & & & \\
\hline
\end{tabular}

The flat tax reform generates a stationary earnings distribution which is more concentrated than under tax regime 1 . The earnings Gini goes from 0.48 up to a maximum of 0.52 and 0.53 for $\sigma=2.0$ and $\sigma=1.5$ respectively. Remarkably, a key force behind this result is, again, the strong increase in labor hours by households with high earnings capacity, and simultaneously, the stagnant or declining labor hours of households with relatively low labor productivity. The general equilibrium consequences of the flat tax are more striking for the case of the wealth distribution. In the case of $\sigma=2.0$ with an exemption level of $20 \%$, the wealth Gini goes up from 0.60 to 0.70 , approximately a $16 \%$ increase relative to the tax regime 1 case. The behavior of the median wealth holdings of households reveals important changes 
in the pattern of asset accumulation brought by the flat tax. Observe that in all cases, median wealth falls, despite the substantial increases in mean wealth. This suggests that the flat tax not only generates an important increase in aggregate (mean) wealth accumulation, but also reduces the incentives for holding wealth for a substantial fraction of households in the model economies. Among these changes in incentives is the drop in the interest rate ${ }^{23}$, the change in size of the transfer of accidental bequests, and the increase in social security benefits implied by the increase in aggregate labor income.

The flat tax reform has a relatively moderate impact on the income distribution, compared to the case of the wealth distribution. The income Gini increases from 0.43 in tax regime 1 , to 0.46 or 0.47 , depending on the model economy considered. Mean income increases with flat tax reform, and contrary to the case of the wealth distribution, median income increases when $\hat{I}^{*}=0.2 \hat{\mathcal{I}}$. Most of the changes occur in the percent share of the upper $20 \%$ of households, which increases after the tax reform up to a maximum of 4.2 percentage points for $\sigma=2.0$, and 4.5 percentage points for the case of $\sigma=1.5$.

Table 11: Percent Share of Income Earned by Quintiles.

\begin{tabular}{|l|ccc|ccccc|}
\hline Model & Top & Top & Top & \multicolumn{5}{|c|}{ Quintile } \\
Economy & $1 \%$ & $5 \%$ & $10 \%$ & 1st & 2nd & 3rd & 4th & 5 th \\
\hline$\sigma=2.0$ & & & & & & & & \\
$\hat{I}^{*}=0.2 \hat{\mathcal{I}}$ & 7.1 & 23.1 & 35.8 & 4.9 & 8.8 & 12.6 & 20.8 & 52.9 \\
$\hat{I}^{*}=0.3 \hat{\mathcal{I}}$ & 7.2 & 23.3 & 36.1 & 5.4 & 8.7 & 12.3 & 20.4 & 53.1 \\
$\hat{I}^{*}=0.4 \hat{\mathcal{I}}$ & 7.3 & 23.6 & 36.3 & 5.8 & 9.3 & 12.0 & 20.0 & 52.9 \\
$\sigma=1.5$ & & & & & & & & \\
$\hat{I}^{*}=0.2 \hat{\mathcal{I}}$ & 7.2 & 22.4 & 36.3 & 4.8 & 8.6 & 12.4 & 20.7 & 53.5 \\
$\hat{I}^{*}=0.3 \hat{\mathcal{I}}$ & 7.2 & 22.7 & 36.6 & 5.3 & 8.5 & 12.1 & 20.3 & 53.7 \\
$\hat{I}^{*}=0.4 \hat{\mathcal{I}}$ & 7.4 & 24.0 & 36.8 & 5.8 & 9.4 & 11.7 & 19.4 & 53.7 \\
& & & & & & & & \\
\hline
\end{tabular}

\footnotetext{
${ }^{23}$ This effect is potentially important for households in tax regime 1 that are exempt from income taxes. For example, in the model economy with $\sigma=2$, for those agents the after tax interest rate $\left(\hat{r}\left(1-t_{k}\right)\right)$ is about $4.5 \%$, which falls after the reform to the market interest rate of $3.6 \%$ for the case of an exemption level of $20 \%$.
} 
It is important to point out the presence of two elements that contribute to moderate the impact on the income distribution of the flat tax reform. First, as the flat tax increases both the wage rate and in most cases the size of aggregate labor input, tax collections out of social security taxes increase. Consequently, social security payments increase equally for all households compared to the case of tax regime 1. This increase in social security transfers, with clear implications on the wealth and income distribution, is an interesting general equilibrium effect that has not been emphasized in the debate on fundamental tax reform. Second, since the size of accidental bequests increases roughly proportional with aggregate wealth, the corresponding lump sum transfer to all households increases also. This latter effect is a consequence of the particular form used here to handle accidental bequests, so it is likely that more realistic ways of handling bequests will not display such equalizing impact on the income distribution ${ }^{24}$.

This section is closed with the examination of the capacity of tax regime 2 to reduce income inequality. As Table 12 demonstrates, the progressive features of tax regime 2 do not reduce the concentration of income in the magnitude that the features of tax regime 1 did.

Table 12: After Tax Income Distribution in Tax Regime 2.

\begin{tabular}{|l|c|ccc|ccccc|}
\hline Model & Income & Top & Top & Top & \multicolumn{5}{|c|}{ Quintile } \\
Economy & Gini & $1 \%$ & $5 \%$ & $10 \%$ & 1st & 2nd & 3rd & 4th & 5th \\
\hline$\sigma=2.0$ & & & & & & & & & \\
$\hat{I}^{*}=0.2 \hat{\mathcal{I}}$ & 0.46 & 7.4 & 23.3 & 36.0 & 5.0 & 9.5 & 12.7 & 20.4 & 52.9 \\
$\hat{I}^{*}=0.3 \hat{\mathcal{I}}$ & 0.45 & 7.4 & 23.3 & 35.9 & 5.7 & 9.2 & 12.6 & 20.1 & 52.4 \\
$\hat{I}^{*}=0.4 \hat{\mathcal{I}}$ & 0.44 & 7.4 & 23.1 & 35.3 & 5.9 & 10.4 & 12.4 & 19.6 & 51.7 \\
$\sigma=1.5$ & & & & & & & & & \\
$\hat{I}^{*}=0.2 \hat{\mathcal{I}}$ & 0.47 & 7.4 & 23.7 & 36.6 & 4.8 & 8.9 & 12.5 & 20.3 & 53.5 \\
$\hat{I}^{*}=0.3 \hat{\mathcal{I}}$ & 0.46 & 7.4 & 23.4 & 36.4 & 5.6 & 9.1 & 12.2 & 19.9 & 53.2 \\
$\hat{I}^{*}=0.4 \hat{\mathcal{I}}$ & 0.44 & 7.4 & 23.4 & 36.0 & 5.8 & 10.6 & 12.2 & 19.1 & 52.3 \\
& & & & & & & & & \\
\hline
\end{tabular}

\footnotetext{
${ }^{24}$ The lump sum transfer of accidental bequests is relatively small, with an average value of $4.1-4.2 \%$ of mean income in tax regime 1 , and $4.8-4.9 \%$ in tax regime 2 . Nevertheless, despite its small magnitude in both tax regimes, movements in the size of the lump sum transfer of accidental bequests affect not only the income distribution, but also the distribution of labor hours and welfare. This problem is explored in section 6 .
} 
Indeed, the reduction in income inequality in tax regime 2 is relatively small, measured by the changes in Gini coefficients and shares of income earned by different percentiles. The implication of this finding is straightforward: for the model economies investigated, both the before tax and after tax income distributions become more concentrated with the adoption of the flat tax.

\section{Welfare}

Having studied quantitatively the positive implications of a flat tax, the crucial normative question on its desirability in welfare terms remains to be answered. This question can be split into two parts. First, is it the case that an aggregate welfare measure, when compared across steady states, increases with the adoption of a flat tax? Secondly, if the answer to the previous question is positive, how welfare gains are distributed across households? Are there cases in which some agents are negatively affected by the reform? If so, who are they?

The aggregate welfare notion studied is the average across households of the expected discounted utility at the beginning of life. At age 1 , the welfare of a household receiving an initial shock $z$ is summarized by the value function $V(0, z, 1)$. Consequently, average welfare in tax regime $i \in\{1,2\}$ is given by

$$
\Omega^{i}=\int_{z \in \mathcal{Z}} V^{i}(0, z, 1) d q(z)
$$

Using the criterion described above ${ }^{25}$, welfare gains are computed as the annual percentage increase in consumption in all ages and states in tax regime 1 , so that households become indifferent between tax regimes ${ }^{26}$. Table 13 shows the results.

\footnotetext{
${ }^{25}$ This criterion has been used in both finitely and infinitely lived setups with heterogeneous agents. See for instance the papers by Imrohoroglu (1989), Imrohoroglu et al (1995), and Aiyagari and McGrattan (1995).

${ }^{26}$ Households are indifferent between tax regimes if $(1+y)^{\nu(1-\sigma)} \Omega^{1}=\Omega^{2}$, where $y$ denotes the common percentage increase in consumption at all ages and states. Then, the welfare gain is $\left(\Omega^{2} / \Omega^{1}\right)^{\frac{1}{(1-\sigma)}}-1$.
} 
Table 13: Welfare Gains (\%)

\begin{tabular}{|c|cc|}
\hline $\begin{array}{c}\text { Exemption } \\
\text { Level }\end{array}$ & $\sigma=1.5$ & $\sigma=2.0$ \\
\hline$\hat{I}^{*}=0.2 \hat{I}$ & 2.3 & 2.7 \\
$\hat{I}^{*}=0.3 \hat{I}$ & 1.9 & 2.7 \\
$\hat{I}^{*}=0.4 \hat{I}$ & 1.3 & 2.5 \\
\hline
\end{tabular}

The results demonstrate that for the cases considered, the steady state welfare gains derived from moving to a flat tax form of taxation are quantitatively important. An immediate implication is that the positive welfare consequences of the flat tax on aggregate capital, aggregate labor and transfers are of considerable magnitude. Indeed, these welfare enhancing effects are capable of compensating for potential negative effects, such as the reduction in exemption levels, and the increase in marginal tax rates for some households. This is a relevant finding, especially since the results were obtained under a calibration for the income tax in tax regime 1 where the lowest level of income subject to income taxation was quite generous (50\% of the mean income of the model economy under tax regime 1).

In terms of the second question posed at the beginning of the section, it turns out that in spite of the large welfare gains shown in Table 13, some agents effectively end up with a lower level of welfare than under tax regime 1. Figures (2) and (3) provide a nice and useful description of the distribution of welfare gains across calibrated initial shocks ${ }^{27}$

\section{Insert Figure 2 and 3 about here}

It is very interesting to observe that the welfare gains display a u-shape when plotted against initial shocks. It follows that the largest increases in consumption occur for agents receiving the largest and the lowest initial shocks. The households who are adversedly affected, however, tend to be

${ }^{27}$ Shock 1 is the lowest shock, while shock 21 is the highest possible one. 
those receiving the middle to middle high shocks ${ }^{28}$. Furthermore, i) initial shocks for which the welfare gains are the lowest tend to increase with the exemption level for labor income and, ii) higher exemption levels tend to reduce the welfare gains of households who experience the lowest welfare gains.

The interpretation of the movements in welfare gains and its distribution across the population due to changes in exemption levels involves at least two central elements. On the one hand, higher exemption levels lead to higher (and distortionary) tax rates in order to balance the government budget and therefore, to lower capital accumulation, a lower level of the aggregate labor input, lower after tax income for high income households and a lower value for social security benefits and the lump sum transfer of accidental bequests. That is, these effects tend to reduce welfare. On the other hand, there is a welfare enhancing effect as higher exemption levels imply a higher after tax income for some households. The key finding that emerges from these benchmark calculations is that despite relatively important aggregate welfare gains, some households are indeed negatively affected by the flat tax, and surprisingly, the higher the exemption level for labor income, the more likely it becomes that some households end up worse off under the flat tax regime.

\section{The Role of Accidental Bequests}

One potential concern about the computational experiments studied in this paper is that, despite its small magnitude, the lump sum transfer of accidental bequests varies with the change in tax regimes as its value is roughly proportional to the size of aggregate wealth. It increases with the adoption of a flat tax, and its value is further decreased with higher exemption levels. In this section, I explore quantitatively the role played by this particular way of handling accidental bequests in the context of tax reform ${ }^{29}$. All transfers

\footnotetext{
${ }^{28}$ Agents that receive the lowest and highest initial shocks constitute a very small fraction of age 1 agents, as their market returns to labor are well below and above the median market return. Agents receiving shock 1 have a market return to labor which is only $6.77 \%$ of the median. Meanwhile, agents experiencing shock 21 receive about 14.8 times the median market return.

${ }^{29} \mathrm{All}$ results in this section are reported for the case of $\sigma=2$.
} 
of accidental bequests are now eliminated, allowing the government to tax all accidental bequests and therefore, use the proceeds to finance government consumption in both tax regimes ${ }^{30}$. This implies a change in condition 5 in the definition of equilibrium that now becomes

$$
\hat{G}=\sum_{j} \mu_{j} \int_{X} T(x, j) d \psi_{j}+\hat{T R}
$$

Results are presented in tables 14,15 and 16. Several points are worth noting here. First, as the government can now use accidental bequests in both tax regimes to finance its consumption, flat tax rates in tax regime 2 are lower than in the baseline calculations. Second, the absence of a lump sum transfer of accidental bequests has important effects on the distribution of labor hours. In this regard, the value of aggregate labor input and mean hours worked in both tax regimes are higher than in the baseline case. Furthermore, a comparison of the results displayed in tables 15 versus those in tables 9 and 6 demonstrate that agents at lower income quintiles work more in both tax regimes, as the negative income effect on labor hours generated by the lump

Table 14: Descriptive Statistics

\begin{tabular}{|l|ccccccccl|}
\hline $\begin{array}{l}\text { Model } \\
\text { Economy }\end{array}$ & $\hat{K} / \hat{Y}$ & $\hat{L}$ & $\begin{array}{c}\text { Mean } \\
\text { Hours }\end{array}$ & $\hat{Y}$ & $\hat{w}$ & $\begin{array}{c}\hat{r} \\
(\%)\end{array}$ & $\begin{array}{c}\tau_{k} \\
(\%)\end{array}$ & $\begin{array}{l}\tau \\
(\%)\end{array}$ & $\begin{array}{l}\text { Welfare } \\
\text { Gains (\%) }\end{array}$ \\
\hline Regime 1 & 3.21 & 0.354 & 0.308 & 0.572 & 1.04 & 5.2 & 11.3 & - & - \\
Regime 2 & & & & & & & & & \\
$\hat{I}^{*}=0.2 \hat{\mathcal{I}}$ & 3.72 & 0.377 & 0.316 & 0.664 & 1.13 & 3.7 & - & 18.5 & 1.8 \\
$\hat{I}^{*}=0.3 \hat{\mathcal{I}}$ & 3.72 & 0.372 & 0.311 & 0.656 & 1.13 & 3.7 & - & 21.7 & 2.4 \\
$\hat{I}^{*}=0.4 \hat{\mathcal{I}}$ & 3.73 & 0.362 & 0.306 & 0.639 & 1.13 & 3.7 & - & 26.0 & 2.4 \\
\hline
\end{tabular}

${ }^{30}$ There are other ways of attacking this problem without a careful modelling of the family. Rios-Rull (1996) eliminates accidental bequests by imposing the existence of a market for one period annuities. where agents can perfectly insure themselves against lifetime uncertainty. Another avenue would be to model the receipt of a bequest as an uncertain event, in which the size of the bequest received is random. 
Table 15: Mean Labor Hours at Different Income Quintiles.

\begin{tabular}{|l|cccc|ccccc|}
\hline $\begin{array}{l}\text { Model } \\
\text { Economy }\end{array}$ & $\begin{array}{c}\text { Top } \\
1 \%\end{array}$ & $\begin{array}{c}\text { Top } \\
5 \%\end{array}$ & $\begin{array}{c}\text { Top } \\
10 \%\end{array}$ & $\begin{array}{c}80- \\
90 \%\end{array}$ & 1st & 2nd & $\begin{array}{c}\text { Quintile } \\
\text { 3rd }\end{array}$ & 4th & 5th \\
\hline Regime 1 & 0.385 & 0.374 & 0.361 & 0.320 & 0.282 & 0.300 & 0.288 & 0.331 & 0.336 \\
& & & & & & & & & \\
Regime 2 & & & & & & & & & \\
$\hat{I}^{*}=0.2 \hat{\mathcal{I}}$ & 0.398 & 0.423 & 0.408 & 0.365 & 0.266 & 0.279 & 0.301 & 0.331 & 0.385 \\
$\hat{I}^{*}=0.3 \hat{\mathcal{I}}$ & 0.396 & 0.420 & 0.404 & 0.357 & 0.284 & 0.266 & 0.286 & 0.321 & 0.379 \\
$\hat{I}^{*}=0.4 \hat{\mathcal{I}}$ & 0.394 & 0.416 & 0.397 & 0.347 & 0.295 & 0.281 & 0.268 & 0.305 & 0.371 \\
\hline
\end{tabular}

sum transfer now disappears. Third, as measured by Gini coefficients, the distribution of income becomes more concentrated in both tax regimes. The key reason for this is the elimination of the lump sum transfer to households. On the other hand, the earnings distribution becomes less concentrated under both tax regimes. This latter result is quite interesting, and it is explained by the fact that, when the lump sum transfer is removed, agents at the lower tail of the earnings distribution increase their labor hours relatively more than agents located at the upper tail of the distribution.

Table 16: Distributional Features

\begin{tabular}{|l|ccccccc|}
\hline $\begin{array}{l}\text { Model } \\
\text { Economy }\end{array}$ & $\begin{array}{c}\text { Earnings } \\
\text { Gini }\end{array}$ & $\begin{array}{c}\text { Wealth } \\
\text { Gini }\end{array}$ & $\begin{array}{c}\text { Income } \\
\text { Gini }\end{array}$ & $\begin{array}{c}\text { Mean } \\
\text { Income }\end{array}$ & $\begin{array}{c}\text { Median } \\
\text { Income }\end{array}$ & $\begin{array}{c}\text { Mean } \\
\text { Wealth }\end{array}$ & $\begin{array}{c}\text { Median } \\
\text { Wealth }\end{array}$ \\
\hline Regime 1 & 0.47 & 0.59 & 0.44 & 0.498 & 0.337 & 1.85 & 1.06 \\
& & & & & & & \\
Regime 2 & & & & & & & \\
$\hat{I}^{*}=0.2 \hat{\mathcal{I}}$ & 0.50 & 0.69 & 0.48 & 0.555 & 0.348 & 2.47 & 0.903 \\
$\hat{I}^{*}=0.3 \hat{\mathcal{I}}$ & 0.49 & 0.69 & 0.47 & 0.545 & 0.335 & 2.44 & 0.884 \\
$\hat{I}^{*}=0.4 \hat{\mathcal{I}}$ & 0.47 & 0.68 & 0.47 & 0.534 & 0.319 & 2.39 & 0.935 \\
& & & & & & & \\
\hline
\end{tabular}


Finally, the analysis of welfare gains due to tax reform, and its distribution across initial shocks (figure 4) shows the effects of the absence of a lump sum transfer and the interaction between exemption levels and resulting tax rates in the present context, as now higher exemption levels lead to lower tax rates than in the baseline case. Notice that aggregate welfare gains are still quantitatively important, but lower than in the baseline calculation. Moreover, in contrast with the baseline case, aggregate welfare gains do not decrease with higher exemption levels for the range of exemption levels considered. Finally, the largest welfare gains still occur for households receiving the lowest and the highest initial shocks. Nonetheless, in the absence of a lump sum transfer, households receiving the lowest initial shocks get a compensating increase in consumption of about $8 \%$, which falls short of the approximately $15 \%$ increase in consumption in the presence of the lump sum transfer of accidental bequests.

Insert Figure 4 here.

\section{Summary and Concluding Remarks}

This paper explores the general equilibrium effects of a revenue neutral tax reform. A dynamic general equilibrium model is first constructed, and then tax structure designed to mimic the prevailing structure in the U.S. is replaced by a flat tax. The quantitative results are derived in an economic enviroment in which progressive features of the current tax code and the proposed flat tax are modelled so that potential distributional impacts of reform can be investigated.

Several key findings emerge from this study. First, the effects of the flat tax reform on capital accumulation appear to be substantial. Consequently, the effects on the wage and the interest rate are of considerable magnitude. As pointed out in the text, this is the result of the replacement of current capital income and income taxes by a consumption based form of taxation. In this regard, this result parallels quantitative findings provided by other authors who studied the general equilibrium impact of consumption taxes against other forms of taxation ${ }^{31}$. Second, the potential impact on labor

\footnotetext{
${ }^{31}$ See Feldstein (1995) for a treatment of consumption taxes that implies an ambiguous response of the interest rate.
} 
supply so emphasized by proponents of the flat tax can be divided into two parts. On the one hand, after the tax reform, mean labor hours decrease in the benchmark calculations. On the other hand, significant changes in the distribution of labor hours are observed. Labor hours supplied by agents at the top of the income distribution substantially increase: households in the upper income quintile increase labor hours from $7 \%$ to $14 \%$. Since these agents are highly productive, this latter effect is the factor behind the overall increase in the value of the aggregate labor input which is observed in most cases. Third, the distributions of earnings, income and in particular wealth become more concentrated in all cases analyzed. This is a key finding, as one of the objections to a flat tax is its potential negative distributional impact. Finally, the impact of the flat tax reform on individual welfare is significant. Calculations for the benchmark parametrization show that aggregate welfare gains derived from moving to a flat tax range from $1.3 \%$ to $2.7 \%$ in consumption terms. This suggests that on the basis of an individualistic welfare measure, a move towards a flat tax is highly desirable. Nevertheless, this crucial result masks how welfare gains are distributed across households. Computations of welfare gains for different earnings abilities at birth reveal that they display a u-shape when plotted against initial ability levels. Whenever accidental bequests are returned to households in lump sum fashion, it is then shown that tax reforms involving high exemption levels, and therefore, high resulting tax rates, can yield welfare losses for some agents.

It is important to note several points in order to place the findings of this paper in perspective. First, as Engen and Gale (1996) have recently stressed in their analysis of fundamental tax reform, the current U.S. tax code contains some of the features of a consumption tax, provided that contributions to several pension plans are tax deductible. Furthermore, earnings on these accounts are taxed only upon withdrawal. Since assets held in these accounts represent a substantial fraction of total financial assets held by U.S. households (approximately $35 \%$ ), it is likely that the positive quantitative impact of a flat tax reform on capital formation and welfare will be reduced. Second, other authors have pointed out that the current federal tax code may involve high compliance costs not modelled here. The relative simplicity embodied in the Hall-Rabushka proposal ("tax forms really can fit on postcards") suggests that the flat tax may well represent an improvement over the existing 
situation ${ }^{32}$. Third, a flat tax reform may increase permanently the growth rate, as has been recently emphasized by Cassou and Lansing (1997). The two previous remarks suggest that there are aditional welfare gains associated with a flat tax that are not included in this analysis. Fourth, the analysis in this paper has not considered any form of human capital accumulation. It is rather clear that a flat tax as a form of consumption taxation will have an impact on this matter that deserves further analysis ${ }^{33}$. Finally, welfare gains are computed in this study by comparing steady state situations without considering issues related to the transition between steady states. This important, but computationally demanding task, is left for future analysis.

\footnotetext{
${ }^{32}$ See Slemrod (1996) for a recent estimation of compliance costs of the U.S. Federal tax code and for a projection of the compliance costs of a flat tax .

${ }^{33}$ See Perroni (1995) for a recent analysis of consumption taxation where households are allowed to accumulate human capital.
} 


\section{Appendix 1: Computation}

Equilibria are computed using the following algortithm:

1. Guess the value for capital $\hat{K}$, labor $\hat{L}$, and transfers of accidental bequests, $\hat{T R}$. In the case of tax regime 2 , guess also a value for the common tax rate $\tau$.

2. Compute factor prices: $\hat{w}=F_{2}(\hat{K}, \hat{L})$ and $\hat{r}=F_{1}(\hat{K}, \hat{L})-\delta$. Obtain the social security transfers, from condition 6 in the definition of equilibrium. In tax regime 1 , compute mean income, the capital income $\operatorname{tax} \tau_{k}$, and the income tax bendpoints.

3. Calculate optimal decision rules: $a(x, j), l(x, j)$, and $c(x, j)$.

4. Calculate values of $\hat{K}, \hat{L}$, transfers $\hat{T R}$ and tax collections that are implied by $a(x, j)$ and $l(x, j)$.

5. If the guessed values from step 1 equal the implied values in step 4, then this is a steady-state equilibrium. Otherwise, guess new values and repeat the above steps.

Steps 3 and 4 above need to be explained. To carry out step 3 , the space of asset holdings is discretized. The asset space takes 401 possible values, ranging from $\underline{\hat{a}}$, to an upper bound $\overline{\hat{a}}$. The distance between gridpoints increases with asset levels ${ }^{34}$. Provided that for all $x \in \mathcal{X}, a(x, N)=0$ since $V(x, N+1) \equiv 0$, decision rules for assets at every gridpoint are computed by solving the age-specific Bellman equations backwards from $j=N-1$. From $j=N-1$ to $j=R+1$, only asset decision rules need to be computed, since labor hours supplied are zero. The asset decision rule is obtained by first bracketing the maximum over the asset grid using a bisection procedure. Once the maximum has been bracketed, the asset decision is obtained by applying a Golden Search method, as implemented by Press et al (1994). To undertake this process, value functions off gridpoints are given by linear interpolation of value functions at gridpoints.

For ages $j=1$ through $j=R$, the problem is relatively more complex due to the presence of the labor supply decision and further complications

\footnotetext{
${ }^{34}$ The asset grid is constructed according to the equation $\hat{a_{k}}=\underline{\hat{a}}+b(k-1)^{2 \cdot}, k \in\{1,401\}$, $b=\overline{\hat{a}} / 400^{2}$.
} 
created by progressive taxation. Notice that at every $j \in\{1, \ldots, R\}$ and $x \in \mathcal{X}$, for every desired $\hat{a}^{\prime}$, the labor decision is a well defined intratemporal optimization problem. Furthermore, the agent's budget constraint is differentiable with respect to labor hours except at the non-differentiable points $\hat{l}_{i}=\left(\hat{I}_{i}-\hat{r} \hat{a}\right) / w e(z, j), i=1, . ., M$ in tax regime 1 , or $\hat{l}=\left(\hat{I}^{*}\right) / w e(z, j)$ in the case of tax regime 2. Labor supply is then obtained by guessing a bracket of income or labor income (depending upon the tax regime considered), obtaining desired labor hours by using the closed form solution determined by first order conditions, and then checking if the implied income or labor income falls within the guessed bracket. For the case of tax regime 1, if when the guessed bracket is $\left(\hat{I_{i-1}}, \hat{I}_{i}\right]$, the implied income belongs to $\left(\hat{I}_{i}, \hat{I}_{i+1}\right]$, and whenever the selected bracket is $\left(\hat{I}_{i}, \hat{I_{i+1}}\right]$, the implied income falls into $\left(\hat{I_{i-1}}, \hat{I}_{i}\right]$, labor hours are those defined by the corresponding non-differentiable point. The same reasoning applies to the case of tax regime 2. The process just described yields for every choice of $\hat{a}^{\prime}$, desired labor hours and taxes paid for all $j \in\{1, \ldots, R\}$ and $x \in \mathcal{X}$. Therefore, with the information on labor hours and taxes paid, the asset decision rule is computed as in the previous case.

Theoretically, step 4 requires the computation of the probability measures $\psi_{1}, \psi_{2}, \ldots, \psi_{N}$. I circumvent this problem by instead performing an equivalent aggregation process by simulating the behavior of a large number of agents. Equilibria are computed by simulating shock histories and consequent decision rules and taxes paid for 20,000 agents per cohort in a stationary equilibrium ${ }^{35}$. Whenever current assets fall outside gridpoints, decision rules and taxes paid are obtained by linear interpolation of values at gridpoints. All the distributional features of the model economies analyzed in the text, are further computed by using the simulated shock histories and implied decision rules obtained for the steady state under consideration.

\footnotetext{
${ }^{35}$ Higher numbers of agents turned out to be irrelevant, in the sense that they do not affect descriptive statistics of the model economies.
} 


\section{Appendix 2: Alternative Wage Processes}

Below, I explore the general equilibrium implications of two alternative wage processes that preserve the same degree of wage concentration than the baseline wage process, as measured by the Gini coefficient ${ }^{36}$. This is done by keeping the same degree of wage inequality at birth than in the baseline case $\left(\sigma_{y_{1}}^{2}=0.29\right)$, but adjusting the regression to the mean parameter and the variance of the shock $\epsilon$ to match the Gini coefficient. The first process is characterized by $\gamma=0.95, \sigma_{\epsilon}^{2}=0.049$ and $\sigma_{y_{1}}^{2}=0.29$. The second one is given by $\gamma=1.0, \sigma_{\epsilon}^{2}=0.008$ and $\sigma_{y_{1}}^{2}=0.29$. That is, the first process displays more regression to the mean than in the baseline case, and the second one displays no regression to the mean at all (i.e. it is a random walk).

Table A2.1: Descriptive Statistics

$$
\left(\gamma=0.95, \sigma_{\epsilon}^{2}=0.049, \sigma_{y_{1}}^{2}=0.29\right)
$$

\begin{tabular}{|l|ccccccccl|}
\hline $\begin{array}{l}\text { Model } \\
\text { Economy }\end{array}$ & $\hat{K} / \hat{Y}$ & $\hat{L}$ & $\begin{array}{c}\text { Mean } \\
\text { Hours }\end{array}$ & $\hat{Y}$ & $\hat{w}$ & $\begin{array}{c}\hat{r} \\
(\%)\end{array}$ & $\begin{array}{c}\tau_{k} \\
(\%)\end{array}$ & $\begin{array}{c}\tau \\
(\%)\end{array}$ & $\begin{array}{l}\text { Welfare } \\
\text { Gains (\%) }\end{array}$ \\
\hline Regime 1 & 3.37 & 0.345 & 0.285 & 0.574 & 1.07 & 4.7 & 11.8 & - & - \\
& & & & & & & & & \\
Regime 2 & & & & & & & & & \\
$\hat{I}^{*}=0.2 \hat{I}$ & 3.88 & 0.358 & 0.281 & 0.646 & 1.16 & 3.2 & - & 21.1 & 2.5 \\
$\hat{I}^{*}=0.3 \hat{I}$ & 3.88 & 0.352 & 0.278 & 0.636 & 1.16 & 3.2 & - & 25.2 & 2.1 \\
$\hat{I}^{*}=0.4 \hat{\mathcal{I}}$ & 3.88 & 0.344 & 0.276 & 0.624 & 1.16 & 3.2 & - & 29.5 & 1.8 \\
\hline
\end{tabular}

Table A2.1 shows the descriptive statistics for the first wage process considered. Two things are worth noting. First, the capital income tax in tax regime 1 and the resulting tax rates under a flat tax are slightly above the ones arising with the baseline wage process. This is a consequence of the now higher degree of uncertainty at the individual level, which entails a

\footnotetext{
${ }^{36}$ All results are reported for the case of $\sigma=2$.
} 
more important precautionary savings motive. Thus, the higher levels of asset accumulation displayed by the model economies (relative to the baseline case) reduce the aggregate return to capital, and thereby, higher tax rates are required.

Second, aggregate welfare gains are still important, but smaller than those obtained for the baseline wage process. This finding is linked to the enhanced insurance role now played by the progressive features of tax regime 1. With the higher levels of idiosyncratic uncertainty implied by the wage process under consideration, it is the case that the progressive income tax of tax regime 1 becomes a more useful device for smoothing purposes than in the presence of the baseline wage process.

Table A2.2 summarizes the distributional implications of tax reform under the first wage process considered. Notice first that, under tax regime 1, the distributions of earnings, income and wealth all become more concentrated as measured by the Gini coefficients. This is interesting, as the cross sectional distribution of wages displays the same concentration as in the baseline case. Second, observe that qualitatively, the impact of the tax reform is the same on the distributions of earnings, wealth and income, which in all cases become more concentrated under tax regime 2.

Table A2.2: Distributional Features

$$
\left(\gamma=0.95, \sigma_{\epsilon}^{2}=0.049, \sigma_{y_{1}}^{2}=0.29\right)
$$

\begin{tabular}{|l|ccccccc|}
\hline $\begin{array}{l}\text { Model } \\
\text { Economy }\end{array}$ & $\begin{array}{c}\text { Earnings } \\
\text { Gini }\end{array}$ & $\begin{array}{c}\text { Wealth } \\
\text { Gini }\end{array}$ & $\begin{array}{c}\text { Income } \\
\text { Gini }\end{array}$ & $\begin{array}{c}\text { Mean } \\
\text { Income }\end{array}$ & $\begin{array}{c}\text { Median } \\
\text { Income }\end{array}$ & $\begin{array}{c}\text { Mean } \\
\text { Wealth }\end{array}$ & $\begin{array}{c}\text { Median } \\
\text { Wealth }\end{array}$ \\
\hline Regime 1 & 0.51 & 0.62 & 0.44 & 0.513 & 0.327 & 1.95 & 1.022 \\
& & & & & & & \\
Regime 2 & & & & & & & \\
$\hat{I}^{*}=0.2 \hat{\mathcal{I}}$ & 0.54 & 0.70 & 0.48 & 0.559 & 0.339 & 2.51 & 0.830 \\
$\hat{I}^{*}=0.3 \hat{\mathcal{I}}$ & 0.54 & 0.70 & 0.48 & 0.547 & 0.322 & 2.47 & 0.783 \\
$\hat{I}^{*}=0.4 \hat{\mathcal{I}}$ & 0.53 & 0.70 & 0.47 & 0.536 & 0.307 & 2.42 & 0.823 \\
& & & & & & & \\
\hline
\end{tabular}


Table A2.3: Descriptive Statistics

$$
\left(\gamma=1.0, \sigma_{\epsilon}^{2}=0.008, \sigma_{y_{1}}^{2}=0.29\right)
$$

\begin{tabular}{|l|ccccccccc|}
\hline $\begin{array}{l}\text { Model } \\
\text { Economy }\end{array}$ & $\hat{K} / \hat{Y}$ & $\hat{L}$ & $\begin{array}{c}\text { Mean } \\
\text { Hours }\end{array}$ & $\hat{Y}$ & $\hat{w}$ & $\begin{array}{c}\hat{r} \\
(\%)\end{array}$ & $\begin{array}{c}\tau_{k} \\
(\%)\end{array}$ & $\begin{array}{c}\tau \\
(\%)\end{array}$ & $\begin{array}{l}\text { Welfare } \\
\text { Gains (\%) }\end{array}$ \\
\hline Regime 1 & 3.13 & 0.324 & 0.290 & 0.518 & 1.02 & 5.5 & 10.8 & - & - \\
& & & & & & & & & \\
Regime 2 & & & & & & & & & \\
$\hat{I}^{*}=0.2 \hat{\mathcal{I}}$ & 3.58 & 0.346 & 0.290 & 0.597 & 1.10 & 4.1 & - & 18.8 & 3.4 \\
$\hat{I}^{*}=0.3 \hat{\mathcal{I}}$ & 3.59 & 0.340 & 0.288 & 0.588 & 1.11 & 4.0 & - & 21.8 & 3.8 \\
$\hat{I}^{*}=0.4 \hat{\mathcal{I}}$ & 3.60 & 0.331 & 0.283 & 0.575 & 1.11 & 4.0 & - & 26.1 & 3.8 \\
& & & & & & & & & \\
\hline
\end{tabular}

The results for the second wage process considered (the random walk case) are shown in tables A2.3 and A2.4. Observe that, in contrast with the patterns of welfare gains found previously, aggregate welfare gains do not decrease with higher exemption levels (for the exemption levels considered).

Table A2.4: Distributional Features

$$
\left(\gamma=1.0, \sigma_{\epsilon}^{2}=0.008, \sigma_{y_{1}}^{2}=0.29\right)
$$

\begin{tabular}{|l|ccccccc|}
\hline $\begin{array}{l}\text { Model } \\
\text { Economy }\end{array}$ & $\begin{array}{c}\text { Earnings } \\
\text { Gini }\end{array}$ & $\begin{array}{c}\text { Wealth } \\
\text { Gini }\end{array}$ & $\begin{array}{c}\text { Income } \\
\text { Gini }\end{array}$ & $\begin{array}{c}\text { Mean } \\
\text { Income }\end{array}$ & $\begin{array}{c}\text { Median } \\
\text { Income }\end{array}$ & $\begin{array}{c}\text { Mean } \\
\text { Wealth }\end{array}$ & $\begin{array}{c}\text { Median } \\
\text { Wealth }\end{array}$ \\
\hline Regime 1 & 0.45 & 0.55 & 0.40 & 0.472 & 0.341 & 1.61 & 1.10 \\
& & & & & & & \\
Regime 2 & & & & & & & \\
$\hat{I}^{*}=0.2 \hat{\mathcal{I}}$ & 0.48 & 0.67 & 0.44 & 0.530 & 0.351 & 2.14 & 0.928 \\
$\hat{I}^{*}=0.3 \hat{I}$ & 0.48 & 0.66 & 0.44 & 0.521 & 0.337 & 2.11 & 0.965 \\
$\hat{I}^{*}=0.4 \hat{\mathcal{I}}$ & 0.47 & 0.65 & 0.43 & 0.510 & 0.318 & 2.07 & 1.065 \\
& & & & & & & \\
\hline
\end{tabular}


Furthermore, these results contrast with the ones previously analyzed for the baseline wage process in the expected direction: i) the model economies under both tax regimes exhibit less accumulation of capital, due to the lower idiosyncratic uncertainty experienced by households; ii) resulting flat tax rates after the reform are lower in all cases; iii) the distributions of income, earnings and wealth are all more concentrated than in the baseline case under both tax regimes. 


\section{References}

[1] Aiyagari, R. and McGrattan, E. (1995), "The Optimum Quantity of Debt"; Staff Report 203, Federal Reserve Bank of Minneapolis.

[2] Auerbach, A. and Kotlikoff, L. (1987), Dynamic Fiscal Policy, Cambridge University Press.

[3] R. Avery and A. Kennickell (1993), "US Household Wealth: Changes from 1983 to 1986"; Research in Economic Inequality , 4, 27-68.

[4] Cassou, S. and Lansing, K. (1997), "Growth Effects of a Flat Tax", mimeo.

[5] Engen. E. and Gale, W. (1996), "The Effects of Fundamental Tax Reform on Saving", in Economic Effects of Fundamental Tax Reform, ed. by Aaron, H. and Gale, W., Brookings Institution Press.

[6] Feldstein, M. (1995), "The Effect of a Consumption Tax on the Rate of Interest"; NBER Working Paper 5397.

[7] Hall, R. and Rabushka, A. (1995), The Flat Tax, 2nd. ed, Hoover Institution Press.

[8] Hansen, G. (1993), "The Cyclical and Secular Behavior of the Labor Input: Comparing Efficiency Units and Hours Worked"; Journal of Applied Econometrics, 8, 71-80.

[9] Henle, P. and Ryscavage, P. (1990), "Earnings Inequality Accelerates in the 1980's"; Monthly Labor Review, December, 3-17.

[10] Herman, T. and Sease, T. (1996), The Flat Tax Primer, Penguin Books, 1996.

[11] Huggett. M. (1996), "Wealth Distribution in Life-Cycle Economies"; Journal of Monetary Economics, 38, 469-494.

[12] Huggett. M. and Ventura, G. (1997), "Understanding Why High Income Households Save More Than Low Income Households"; mimeo, University of Illinois. 
[13] Hurd, M. (1989), "Mortality Risk and Bequests"; Econometrica,57, 779813.

[14] Imrohoroglu, A., Imrohoroglu, S. and Joines, D. (1995), "A Life Cycle Analysis of Social Security"; Economic Theory, 6, 83-114.

[15] Imrohoroglu, A. (1989), "Costs of Business Cycles with Indivisibilities and Liquidity Constraints"; Journal of Political Economy", 97, 1364 1383 .

[16] Imrohoroglu, S. (1992), "A Quantitative Analysis of the Optimal Capital Income Structure under Incomplete Markets", mimeo, University of Southern California.

[17] Kotlikoff, L. (1995), "Prepared Statement by Laurence J. Kotlikoff", in Flat Tax Proposals, Hearings Before the Commitee on Finance, United States Senate.

[18] Laitner, J. (1992), "Random Earnings Differences, Lifetime Liquidity Constraints and Altruistic Intergenerational Transfers"; Journal of Economic Theory, 58, 135-170.

[19] Perroni, Carlo (1995), "Assesing the Dynamic Efficiency Gains of Tax Reform when Human Capital is Endogenous"; International Economic Review.36, 907-925.

[20] Prescott. E. (1986), "Theory Ahead of Business Cycle Measurement"; Federal Reserve Bank of Minneapolis Quarterly Review , 9-22.

[21] Press, W., Teukolsky, S., Vetterling, W. and Flannery, B. (1994), Numerical Recipes in Fortran: The Art of Scientific Computing, Cambridge University Press, 2nd. ed.

[22] Quadrini. V., and Rios Rull, J.V. (1996), "The Distribution of Income, Wealth, and Earnings: Facts and Models", Staff Report, Federal Reserve Bank of Minneapolis, 1996.

[23] Quadrini, V. (1996), "Entepreneurship, Savings, and Social Mobility", mimeo. University of Pennsylvania. 
[24] Rios-Rull, J.V. (1996), "Life Cycle Economies and Aggregate Fluctuations"; Review of Economic Studies , 63, 465-489.

[25] Rios-Rull, J.V. (1995), "Models With Heterogeneous Agents", in T. Cooley, ed., Frontiers of Business Cycle Research, Princeton University Press.

[26] Ryscavage, P. (1994), "Gender Related Shifts in the Distribution of Wages", Monthly Labor Review, July, 3-16.

[27] Ryscavage, P. (1995), "A Surge in Growing Income Inequality?" ,Monthly Labor Review, August, 51-61.

[28] Slemrod, J., "Which is the Simplest Tax System of Them All?", in Economic Effects of Fundamental Tax Reform, ed. by Aaron, H. and Gale, W., Brookings Institution Press.

[29] Social Security Administration (1992), Life Tables for the US Social Security Area, Actuarial Study 107.

[30] Stokey, N. and Rebelo, S. (1995), "Growth Effects of Flat-Rate Taxes"; Journal of Political Economy; 103; 519-550.

[31] Wolff, E. (1987), Estimates of Household Wealth Inequality in the US, 1962-1983; Review of Income and Wealth, 231-57. 
Figure 1: Wage Profile

(Ratio to the Overall Mean)

$\therefore$
$\therefore$

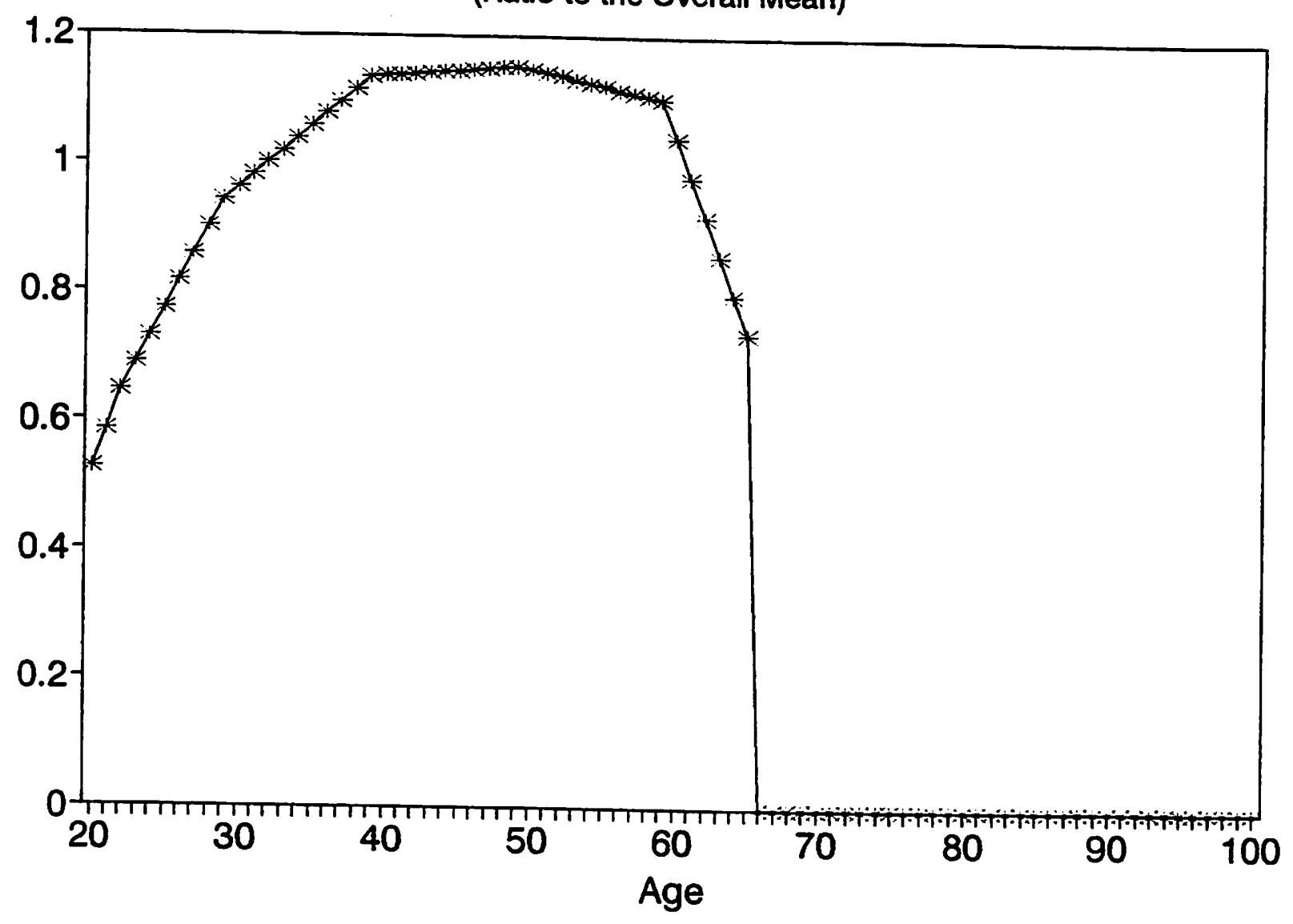


Figure 2: Welfare Gains Sigma $=2$.

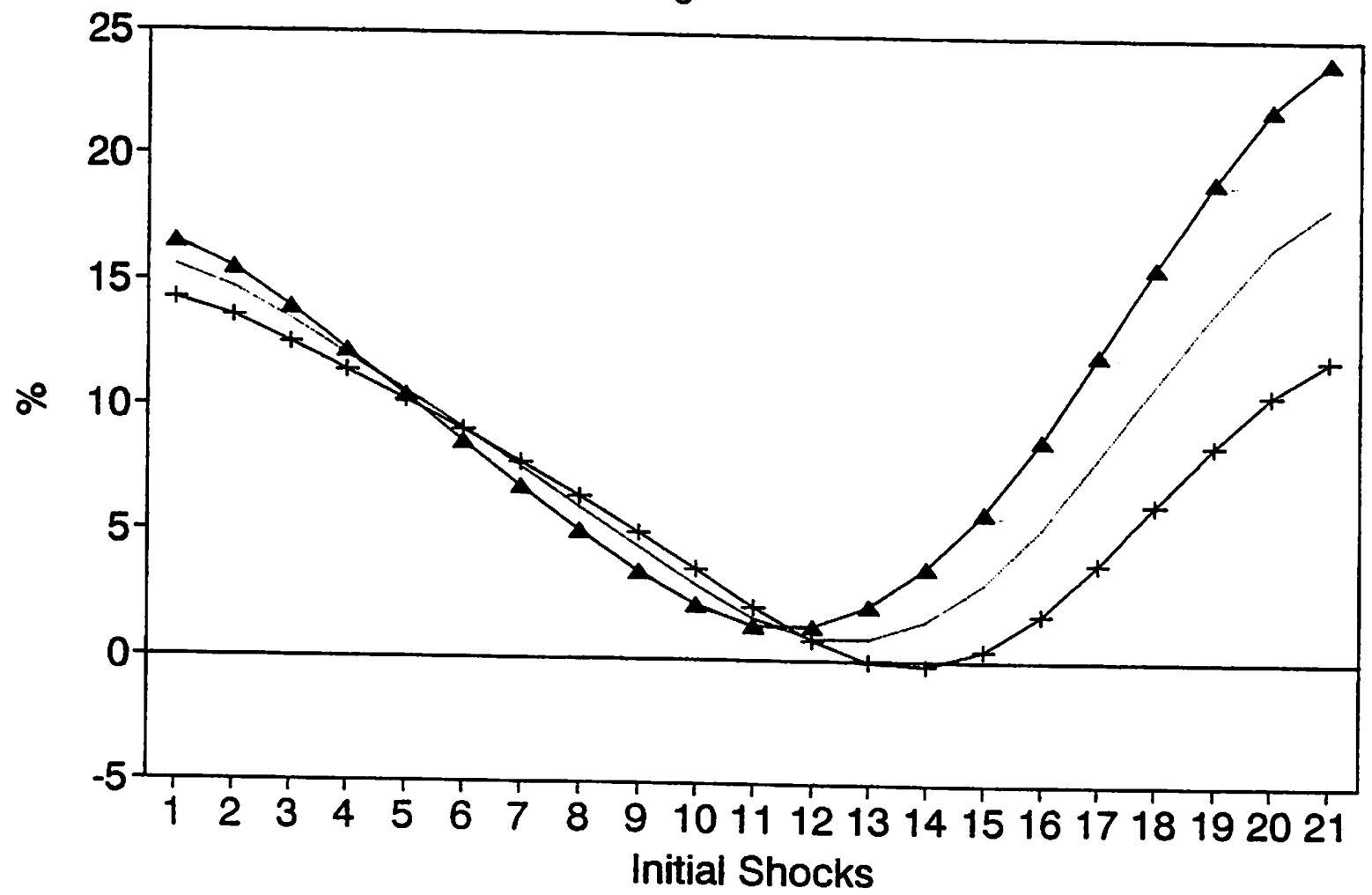

$\not$ Ex. Level $=20 \%$ - Ex. Level $=30 \%$ - Ex. Level $=40 \%$ 
Figure 3: Welfare Gains

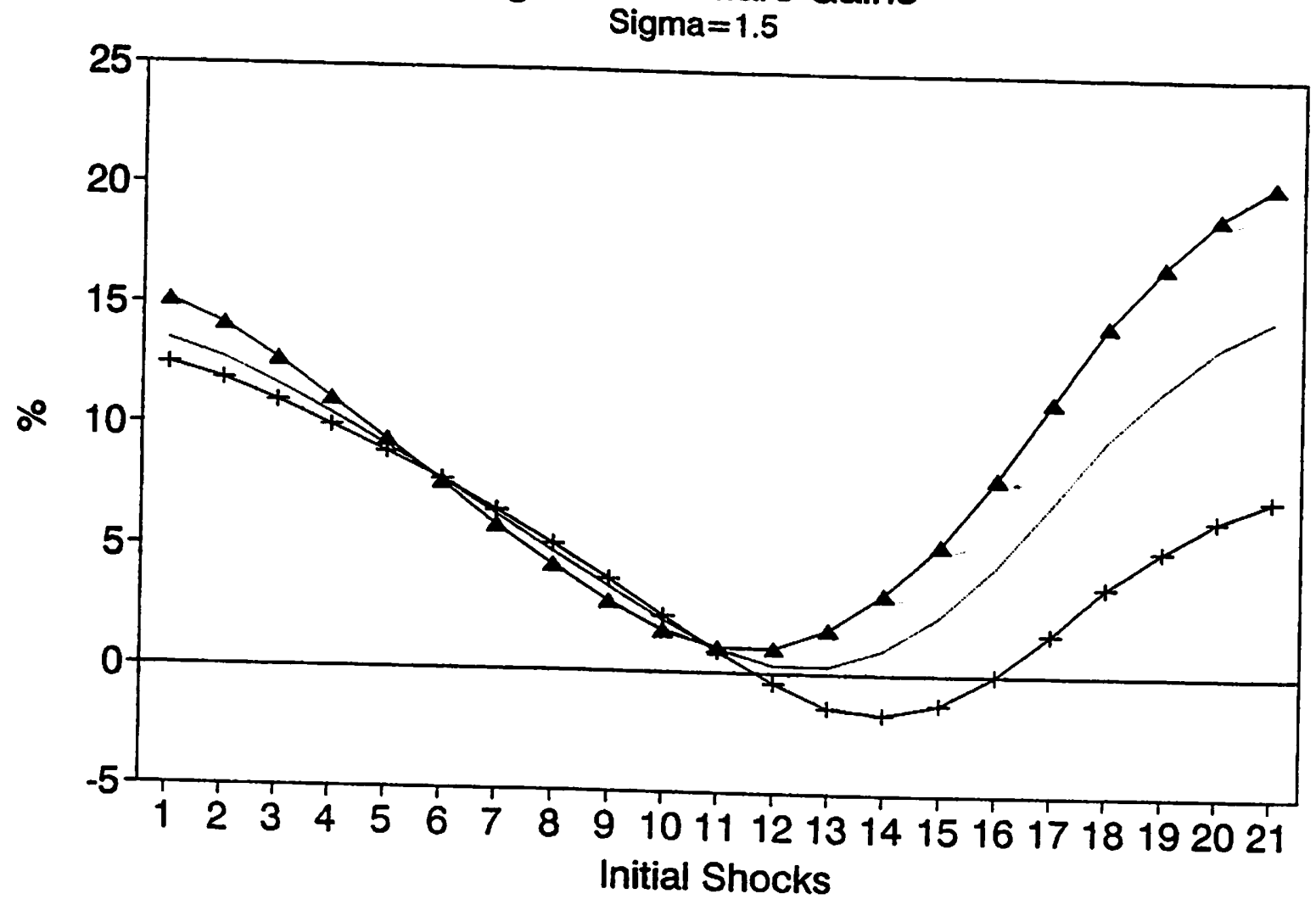

Ax. Level $=20 \%-$ Ex. Level $=30 \%$ - Ex. Level $=40 \%$ 
Figure 4: Welfare Gains

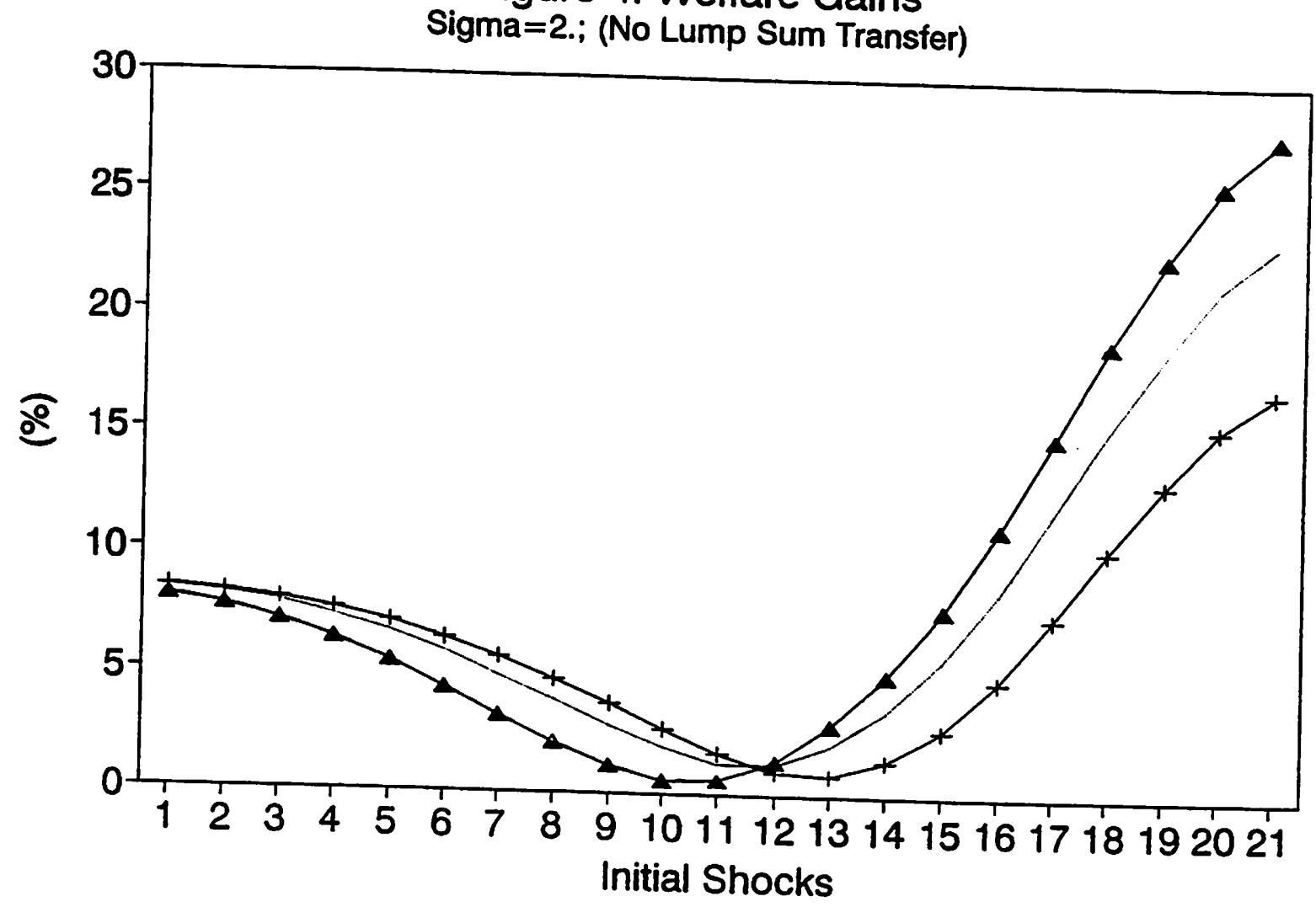

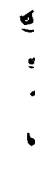

L- Ex. Level $=20 \%-$ Ex. Level $=30 \%-$ Ex. Level $=40 \%$ 